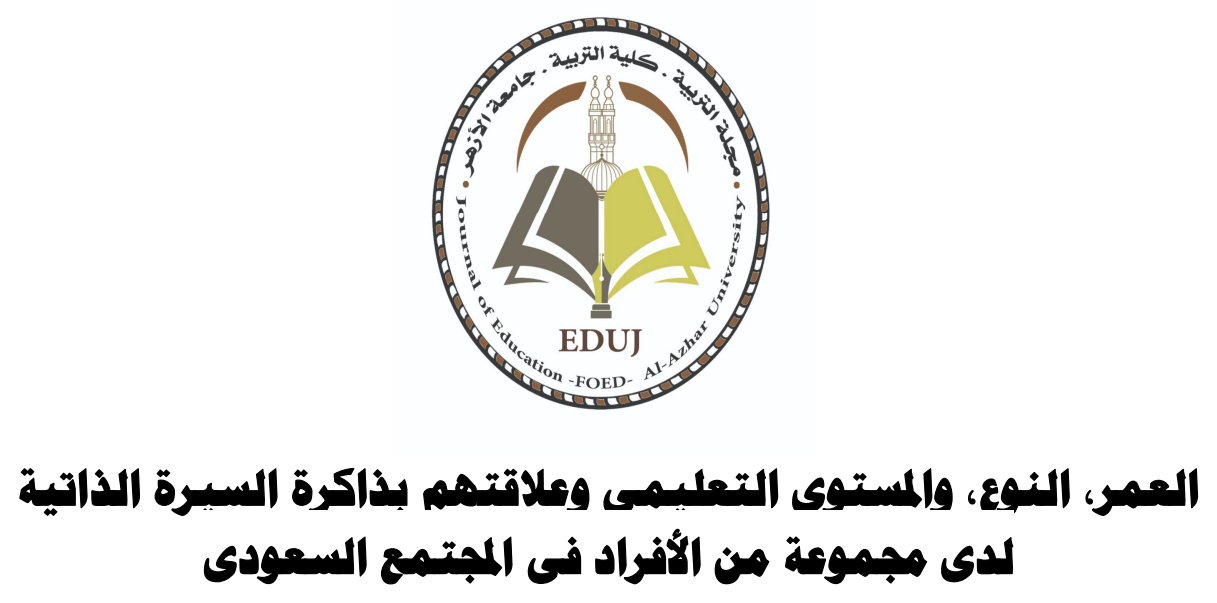

\title{
إعداد
}

د/ عبد الرحمن بن سايسمان النمالة

أستاذ النهمو العقلي- المعرفي المشارك

قسم علم النفس - كلية العلوم الاجتهاعية بالرياض

جامعة الإهام هممد بن سعود الإسلاهية 


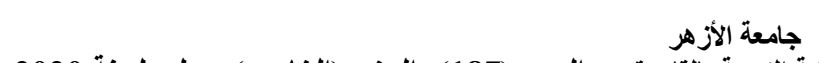

$$
\begin{aligned}
& \text { كلية التربية بالقاهرة العدد: (187)، الجزء (الخامس)، يوليو لسنة 2020م } \\
& \text { مجلة التربية }
\end{aligned}
$$

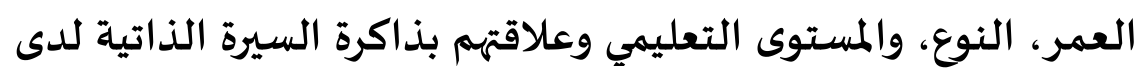

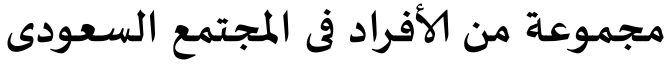

عبد الرحمن بن سليمان النملة قسم علم النفس،كلية العلوم الاجتماعية بالرياض، جامعـة الإمام محمدل بن سعود الإسلامية، المملكة العربية السعودية. asnamlah@imamu.edu.sa البريد الككتروني:

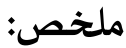

فحص البحث الحالي تأثير كل من العمر والنوع والمستوى التعليمي على ذاكئ ذاكرة السيرة

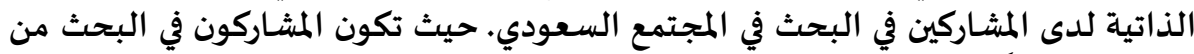

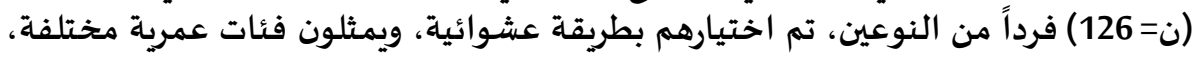

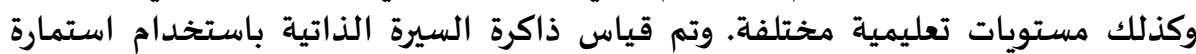

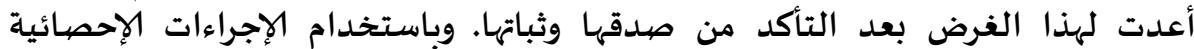

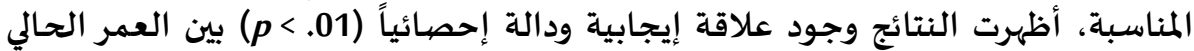

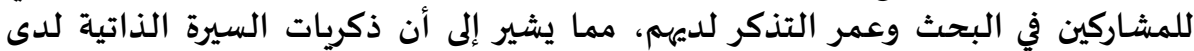

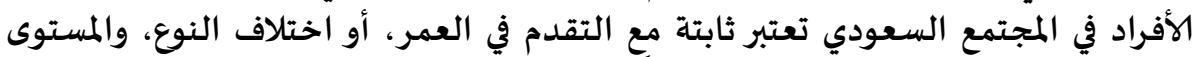

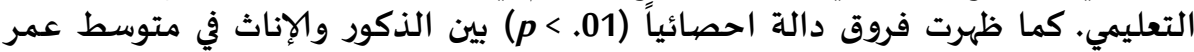

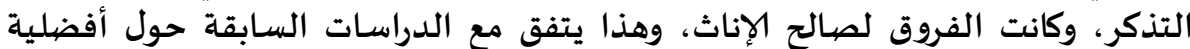

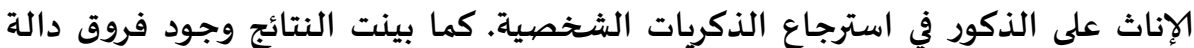

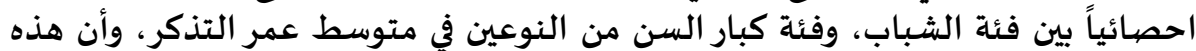

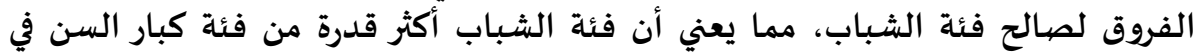

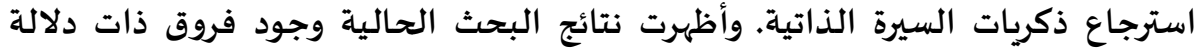

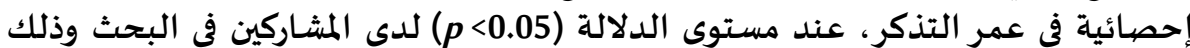

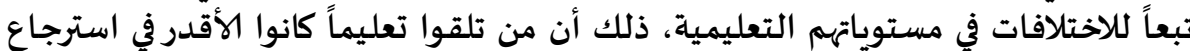

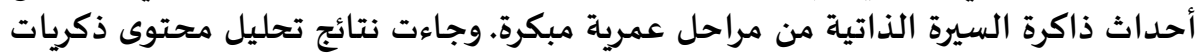

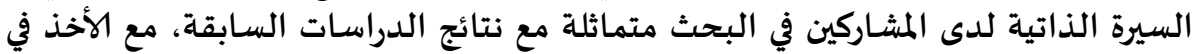

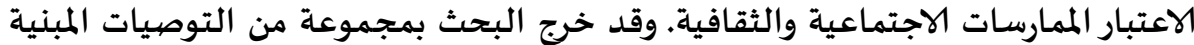

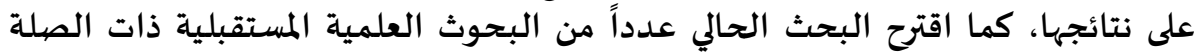
بموضوعها والاقتراح بتطوير الأفكار والنتائج التي خلصت اليت إليها.

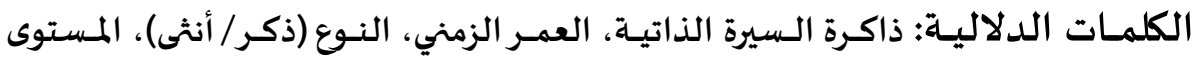




\title{
Abdulrahman S. Al-Namlah \\ Department of Psychology-College of Social Sciences in Riyadh, Al-Imam Muhammad Ibn Saud Islamic University, KSA.
}

\section{Email: asnamlah@imamu.edu.sa}

\begin{abstract}
The current study examined the impact of age, gender, educational level on autobiographical memory (AM) among a sample of individuals in the Saudi society. The study sample consisted of $(\mathrm{n}=$ 126) participants of both sexes, who were randomly selected and are represented different age groups, as well as different educational levels. AM was measured by using an inventory prepared for the purpose of the study, and was tested for its validity and reliability. The results showed a positive and statistically significant relationship ( $p$ $<.01)$ between the current age of the participants and the age of their remembrance, which indicates that personal memories of the individuals in the Saudi society are considered constant with either the increase in age, or differences in gender and educational level. There were also statistically significant differences $(p<.01)$ between males and females in the average age of remembering, and the differences were in favor of females, and this is consistent with previous studies on the preference of females over males in retrieving personal memories. The results also showed that there are statistically significant differences between youth and elderly participants of both sexes in the average age of recall, and that these differences were in favor of the youth category, which means that youths are more capable than elders in retrieval of AM. The results also indicated statistically significant differences $(p<.05)$ in the average age of remembering among the participants according to differences in their educational levels. Where those who received an education were more able to retrieve autobiographical memories from early ages. The content of autobiographical memories among participants in the current study are in line with those found in previous research, taking into account differences in social and cultural practices. The study came out with a set of recommendations based on its results, together with issues arising from those findings.
\end{abstract}

Keywords:_Autobiographical Memory - Chronological Age - Gender - Educational Level 


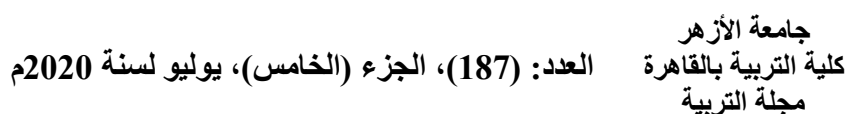

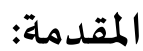

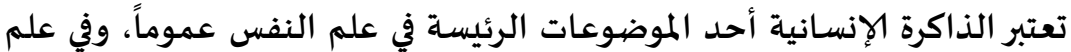

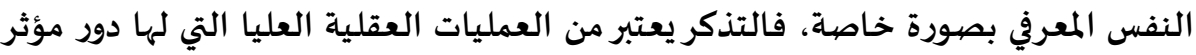

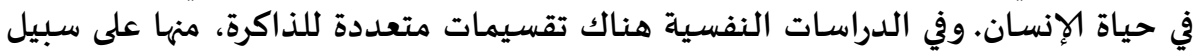

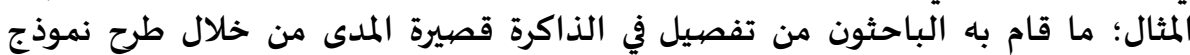
الذاكرة العاملة (Woddeley, 1990, 1993, 2000; Grossberg, 1971; (Working Memory) توالتفصيل أيضا في الذاكرة طويلة المدى، حيت ميز (Mongillo, Barak \& Tsodyks, 2008) تولفنج (1972م-1983م) بين نوعين من الذاكرة طويلة المدى وهما؛ الذئ الذاكرة الدلالية (Semantic Memory) والذاكرة العرضية (Tulving, 1972, (Episodic Memory)

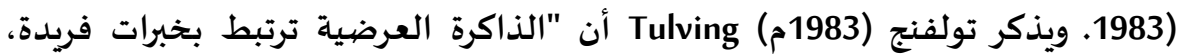

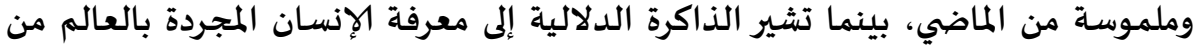

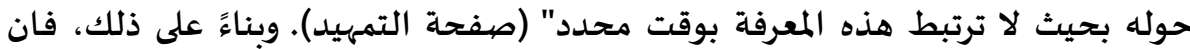

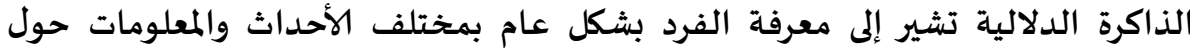

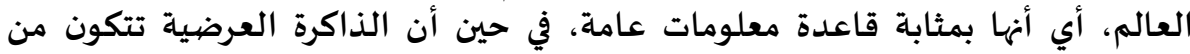

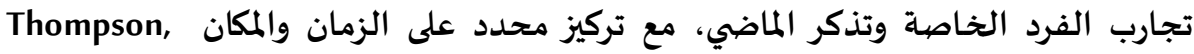
.(Skowronski, Larsen \& Betz, 1996)

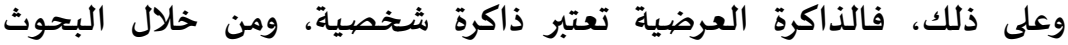

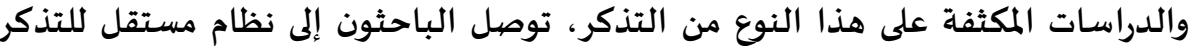

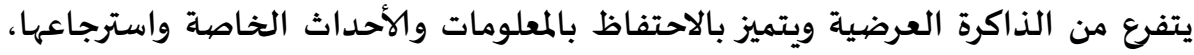

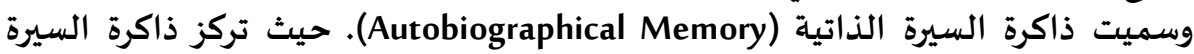

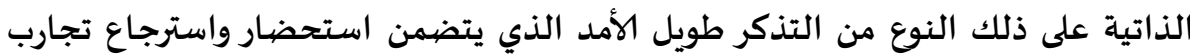

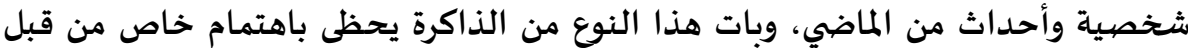

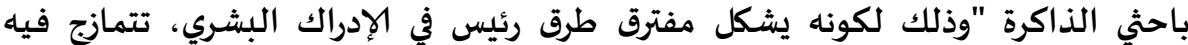

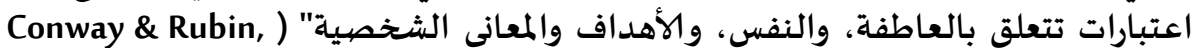

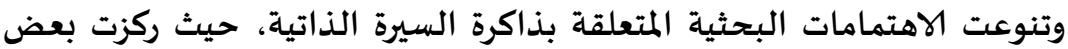

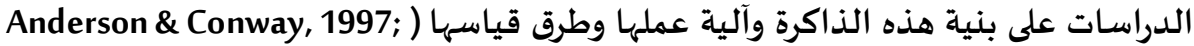

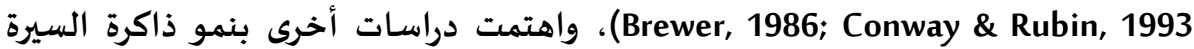
الذاتية والعوامل المؤثرة فيها ( Al-Namlah, Meins \& Fernyhough, 2012; Hudson, (1986; Nelson \& Gruendel, 1981 Nelson \& Ross, 1980

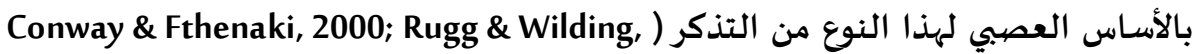

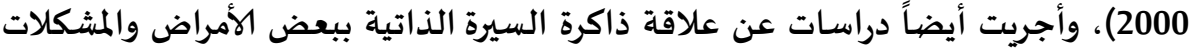

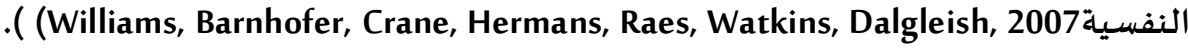

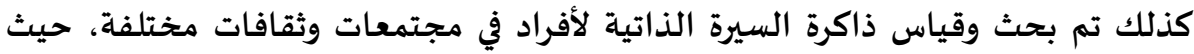

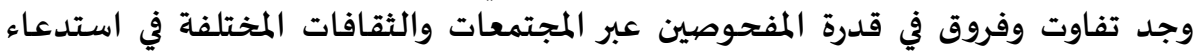


أحداث ومواقف شخصية من الماضي، وتم عزو تلك الفروق إلى العوامل والممارسات الاجتماعية-الثقافية الخاصة بكل مجتمع (Fivush \& Nelson, 2004; Wang, 2016).

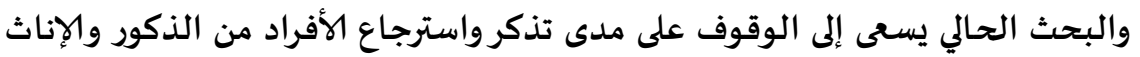

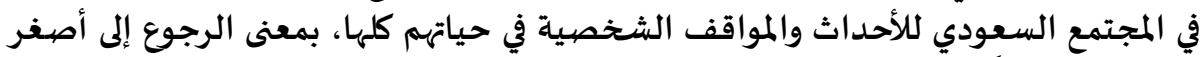
عمروتذكر شيئًا من مواقفه وأحداثه.

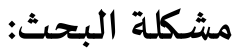

كما تمت الإشارة في المقدمة، ذاكرة السيرة الذاتية هي فرع من الذاكية الذاكرة طويلة

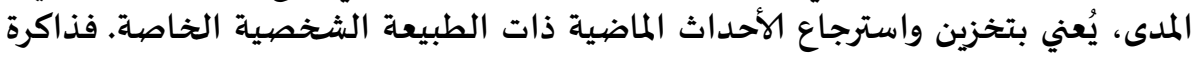

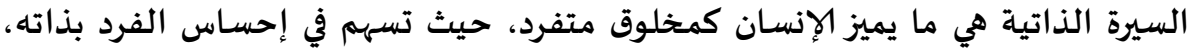

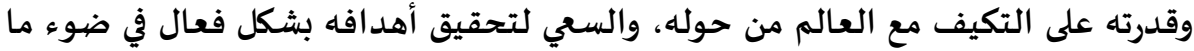
يمتلك من سجل شخصي تراكمي لخبرات ومواقف سابقة ( Conway, Singer \& Tagini, )

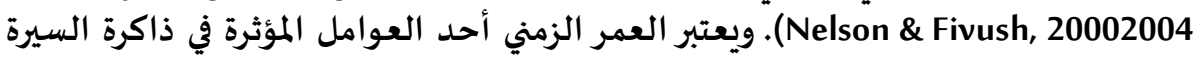

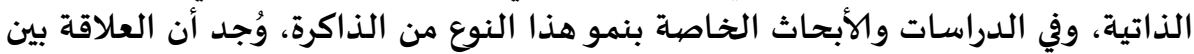

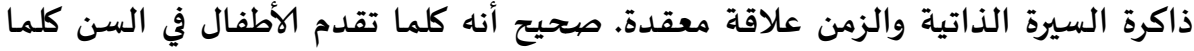

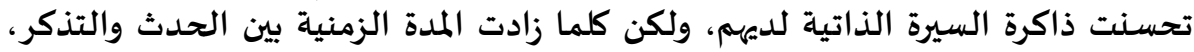

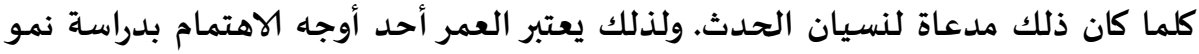

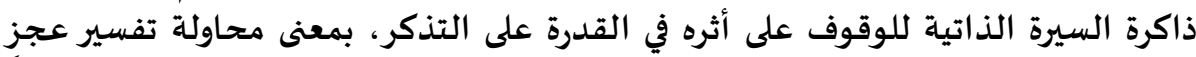

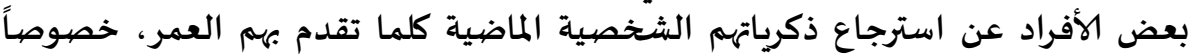
تلك التي حدثت في مرحلة الطفولة المبكرة (Schlagman, Kvavilashvili \& Schulz, 2007).

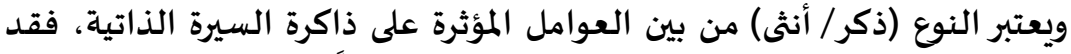

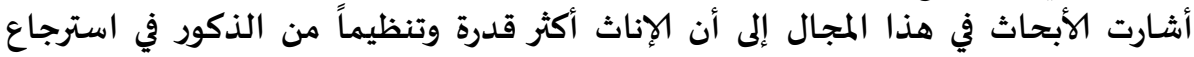

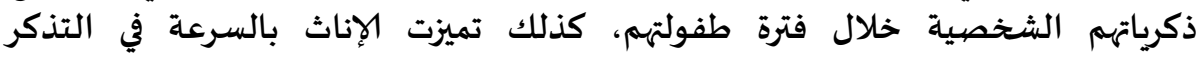

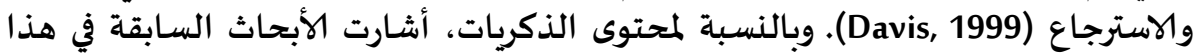

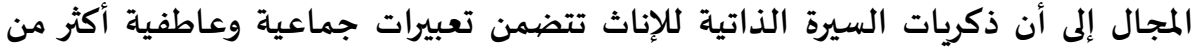

الذكور (Kristina, Sverker, Fredrik, Marie \& Johan, 2019).

أيضاً فان المستوى التعليمي يعد من العوامل المؤثرة على صياغة الأحداث

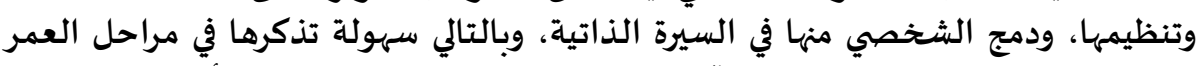

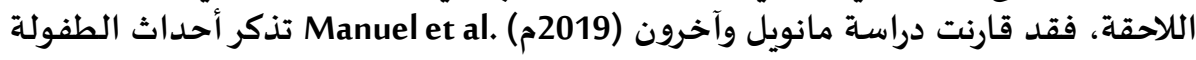

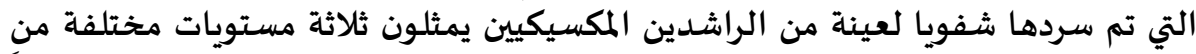

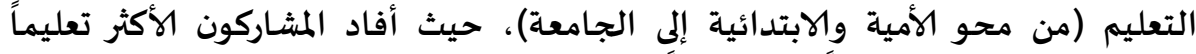

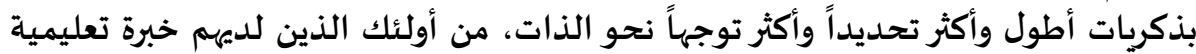

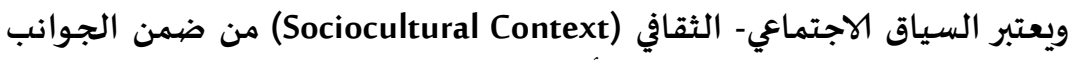

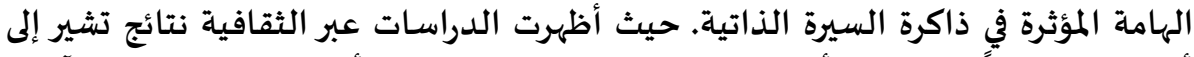

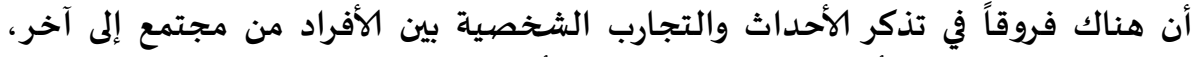

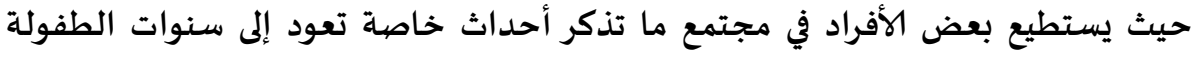




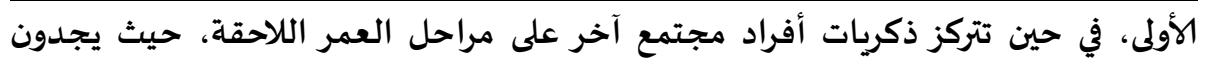

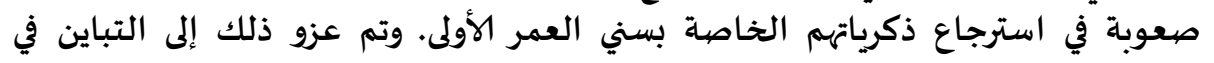

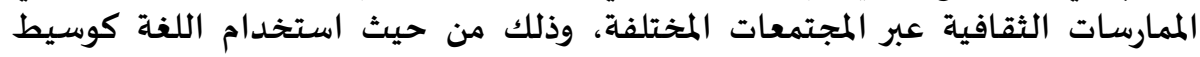

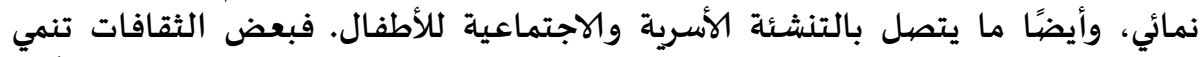

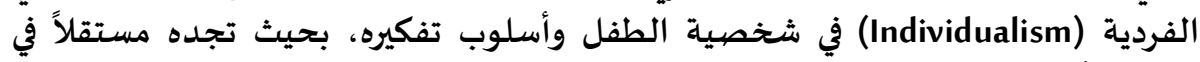

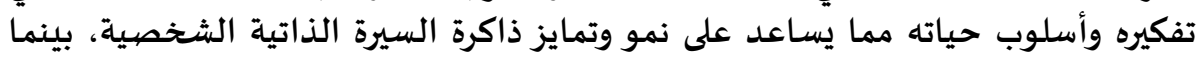

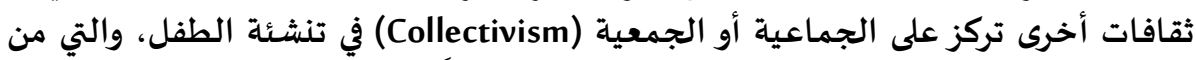

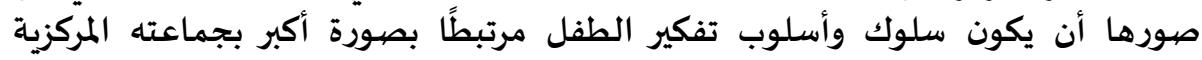
كالأسرة أو القبيلة أو المجتمع ككل، وبناءً عليه تتسم ذوكل ذكرياته بالعمومية (Nelson, 1993).

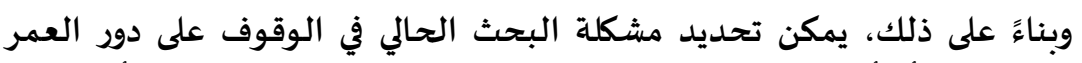

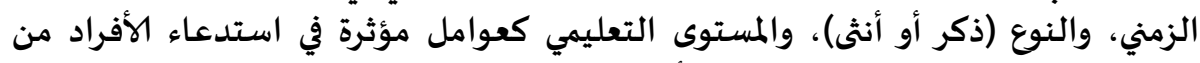

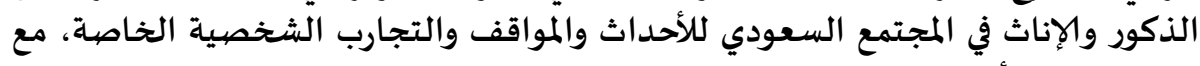

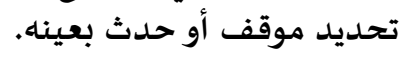
أسئلة البحث: - 20 - 20

سعى البحث الحالي للإجابة عن الأسئلة الآتية:

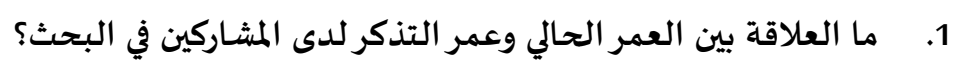
2.

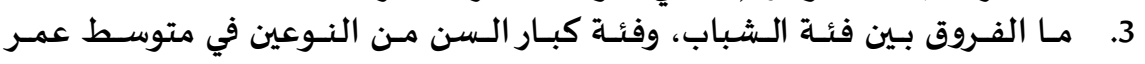
التذكر؟

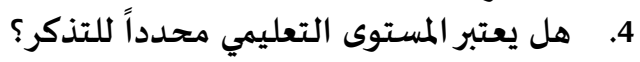

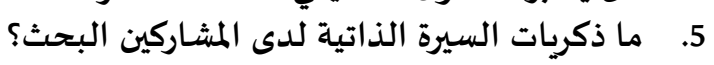

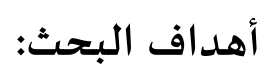

سعى البحث الحالي لتحقيق الأهداف الآتية:

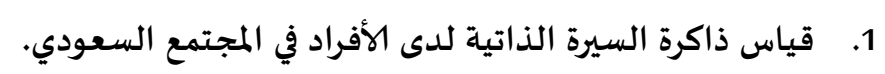
2. التعرف على طبيعة ذاكرة السيرة الذاتية لدى الأفراد في المجتمع السعودي. 3. معرفة العلاقة بين العمر الزمني وذاكرة السيرة الذاتية. 4. معرفة الفروق في ذاكرة السيرة الذاتية بين الذكور والإناث في المجتمع السعودي. 5. الوقوف على تأثير المستوى التعليمي على ذاكرة السيرة الذاتية.

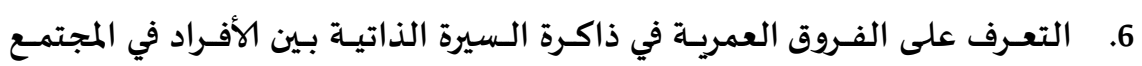
السعودي. 
أهميـة البحث: تظهر أهمية البحث من عـدة اعتبارات على المستويين النظري والتطبيقي يمكن الإشارة إلى أهمها فيما يلي:

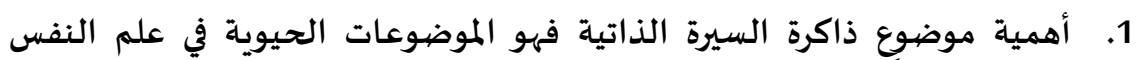
المعرفي عموماً، وفي دراسـات الذاكرة الإنسانية على نحوة الموة خاص.

2. ذكريات السيرة الذاتية تعتبر تمثيلات ذات طابع شخصي مهرم في في الذاكرة

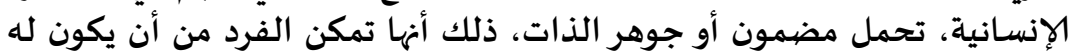
ماض وحاضر ، مما يساعده على توجيه سلوكه المستقبلي.

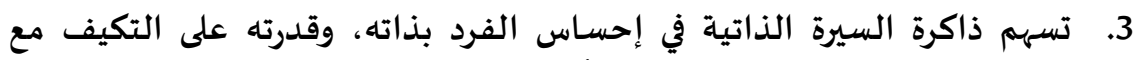

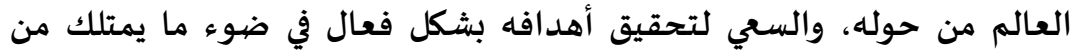
سجل شخصي تراكمي لخبرات ومواقف سابقة الهُة

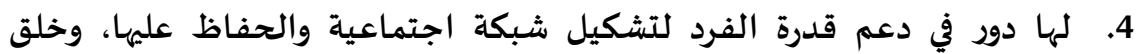
شعور مستمر بالذات، والخبرة في التعامل مع العواطف لفيكة الإيجابية والسية والسلبية.

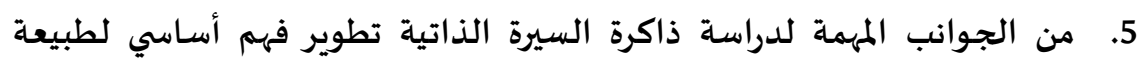

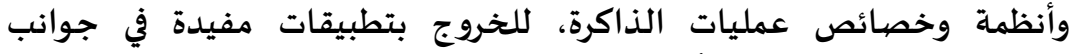
مختلفة، سواء كانت علمية أو على مستوى الحياة اليومية للفرد. 6. ندرة الدراسات العربية عن ذاكرة السيرة الذاتية يعد دافعاً لإجراء البحث الحالي. 7. بعض التحديات والمتغيرات المعاصرة التي يمكن أن تؤثر على ذاكرة السيرة الذاتية

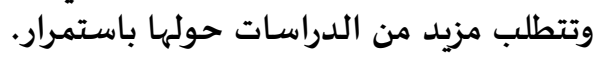

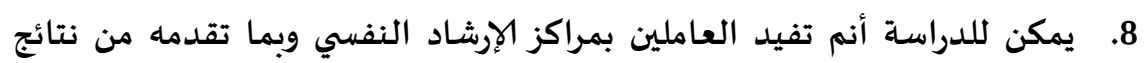

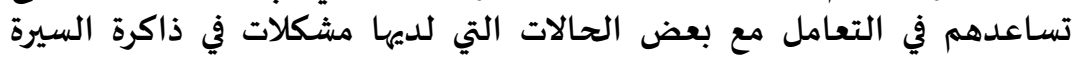

9. يمكن للدراسة أن تفيد الباحثين المهتمين بالمجال من خلال توجيههم لإجراء بحوث

$$
\text { مصيطلحات البحث: أخرى مرتبطة بموضوع البحث الحالي. }
$$

ذاكرة السيرة الذاتية Autobiographical Memory:

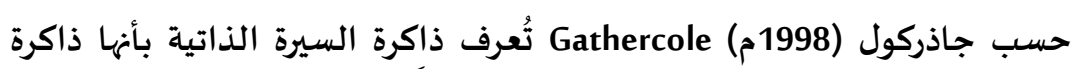

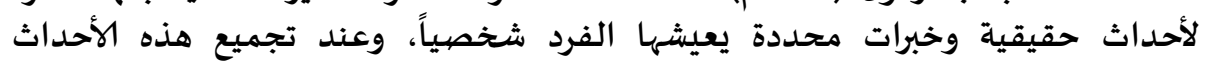

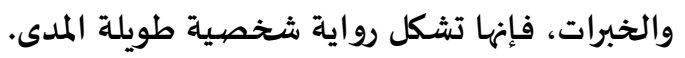

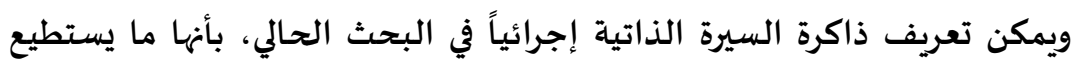

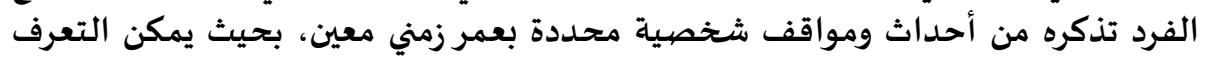
على ذلك من خلال استجابته على أداة البحث. 


$$
\text { كلية التربية بالقاهرة العدد: (187)، الجزبة (الخامس)، يوليو لسنة 2020م }
$$

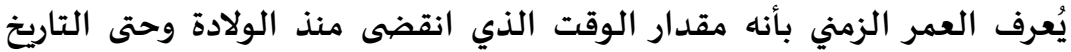

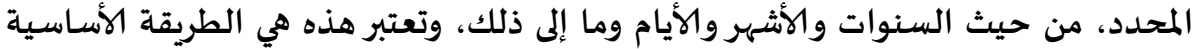

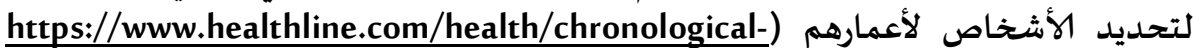

(, 2020ageing

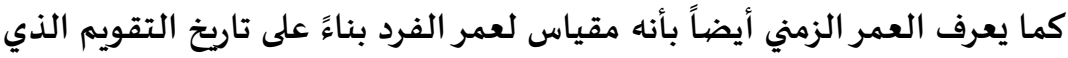

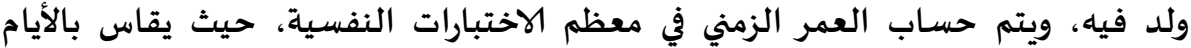

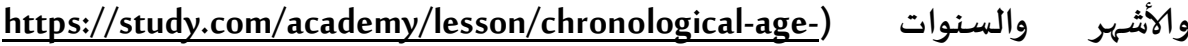

.(, 2020definition-lesson-quiz.html

\section{عمر التذكر Remembering Age:}

يعرف وود (2018م) Wood عمر التذكر بأنه أقصى أو أصغر عمر يمكن أن

$$
\text { يسترجع الفرد ذكرياته الشخصية التي حدثت فيه. }
$$

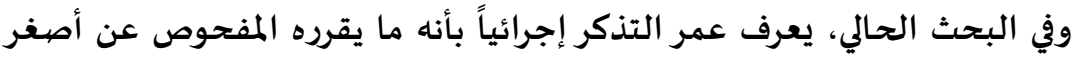

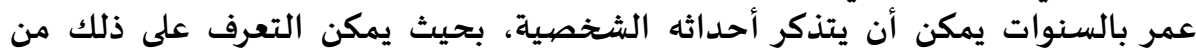

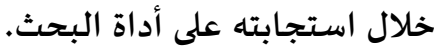

المستوى التعليمي Educational Level:

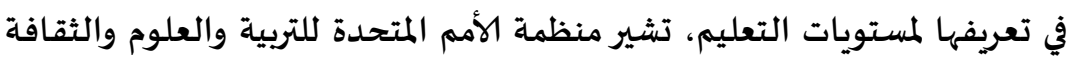

(اليونسكو) إلى التصنيف الدولي المعياري للتعليم ( The framework of the International

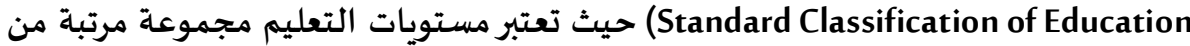

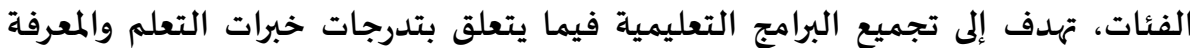

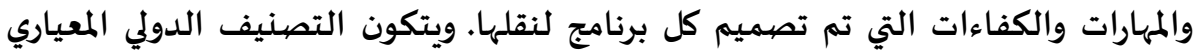

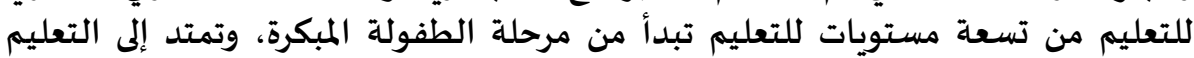
العالي (المصيدر:

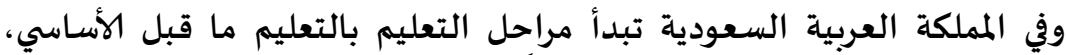

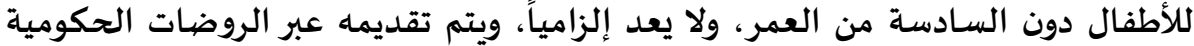

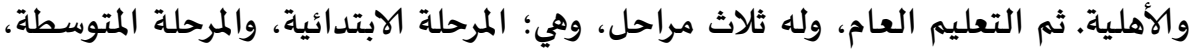

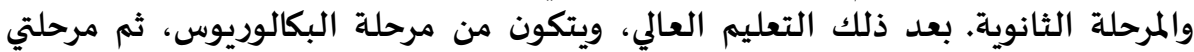

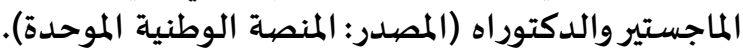

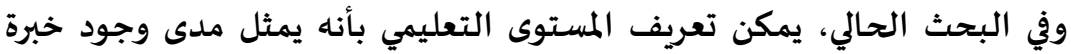

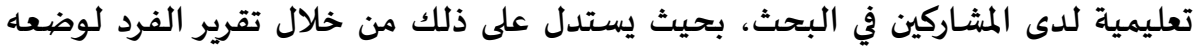
التعليمي، والذي يمكن التعرف عليه من خلال استجابته على أداة البحثث. 


\section{حلدود البحث:}

1. الحدود المكانية: تم إجراء هذا البحث في مدينة الرياض بالمملكة العربية السعودية.

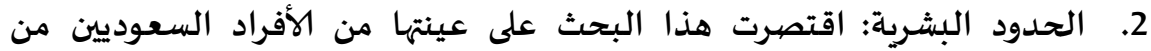

النوعين.

3. الحدود الزمانية: تم تنفيذ البحث في العام 1439هـ الموافق للعام 2018م.

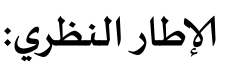

اهتم هذا الجزء من البحث بتقديم استعراض نظري موجز لذاكرة السيرة الذاتية

من حيث بنيتها ونموها، وكذلك الفروق الفردية والجمعية في ذاكرة السيرة الذاتية.

بنية ذاكرة السيرة الذاتية:

ينظر بعـض البـاحثين إلى ذاكرة السيرة الذاتيـة (Autobiographical Memory)

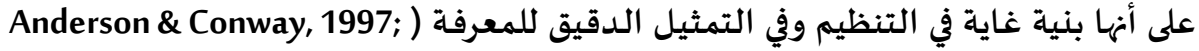

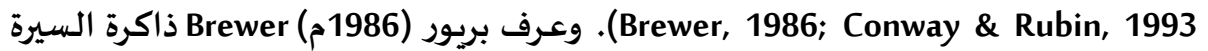

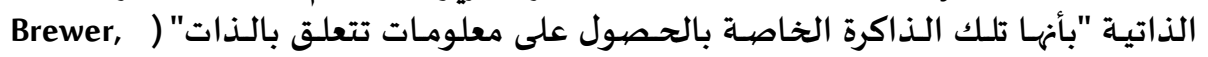
26

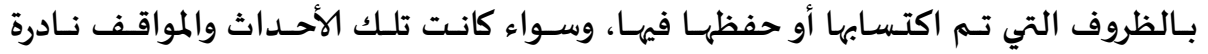

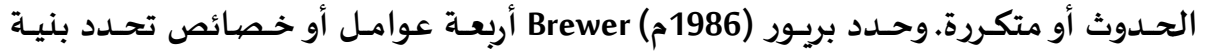

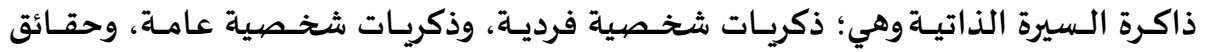

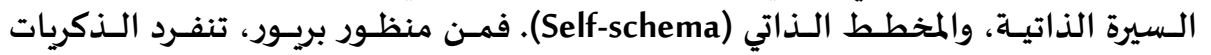

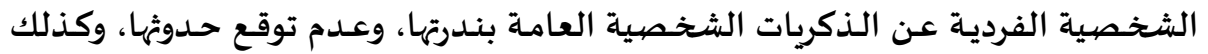

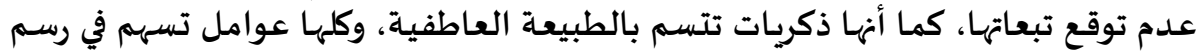

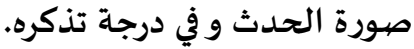

وتتشكل الذكريات الشخصية الفردية من هذه الخصيائص مجتمعةة، وعادة ما يـتم

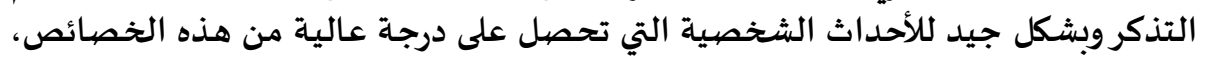

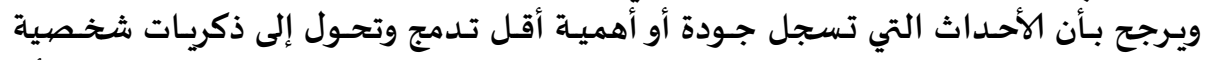

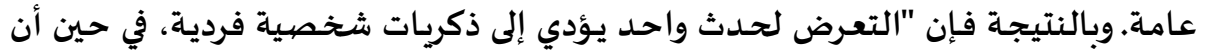

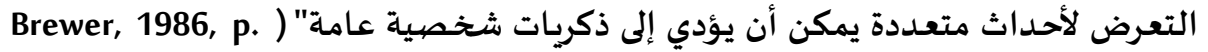

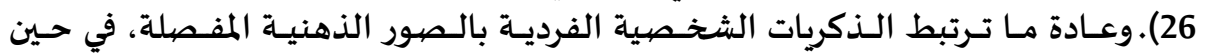

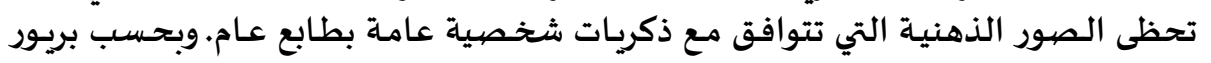

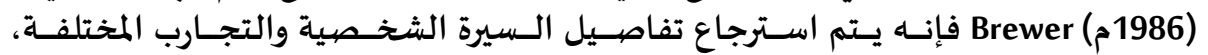

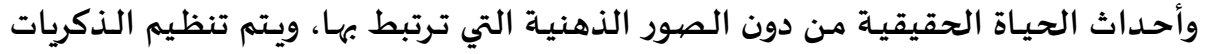

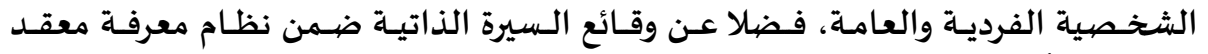
يعرف على أنه المخطط الذاتي.

وأشسار كونـواي وروبين (1993م) Conway and Rubin إلى وجسود ثلاثة مستويات

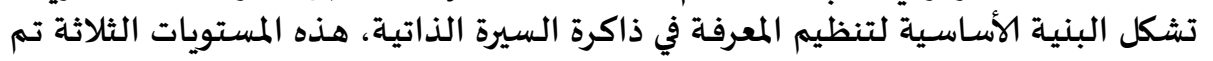

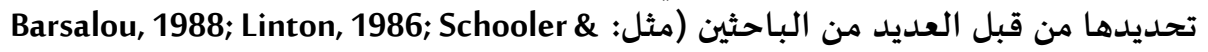

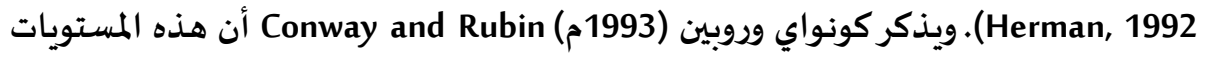


الثلاثة هي؛ فترة الحياة، والأحداث العامة، ومعرفة حدث معيدة مئن وتمثل فترة الحياة المستوى

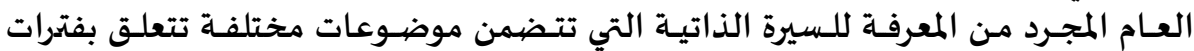

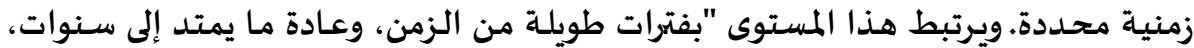

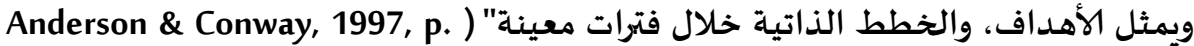

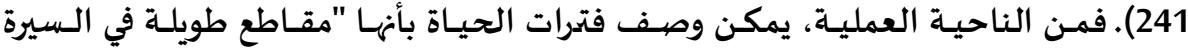

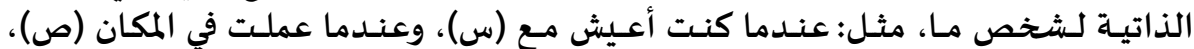

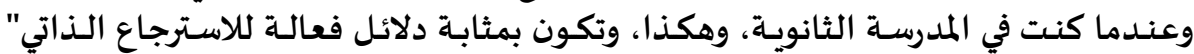

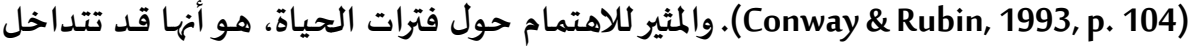

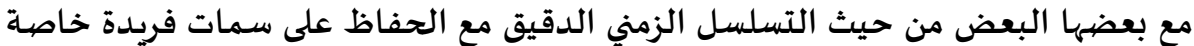

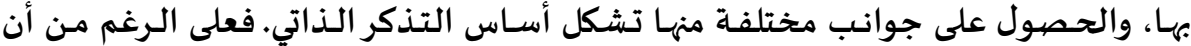

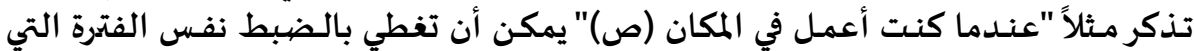

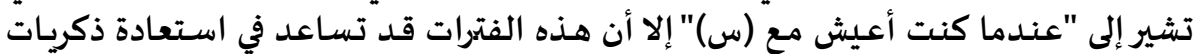
مختلفة من السيرة الذاتية (Brown, Shevell, \& Rips, 1986).

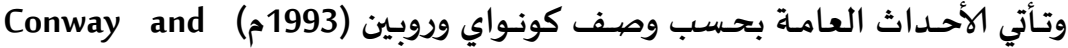

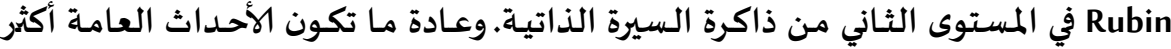

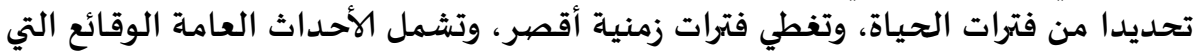

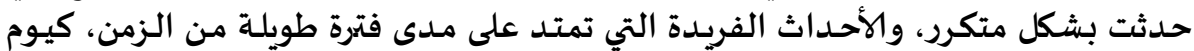

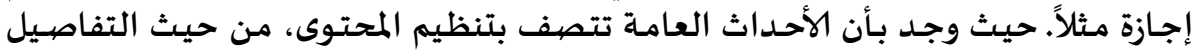

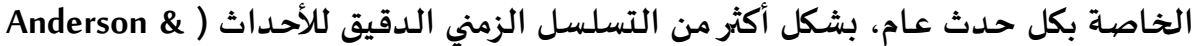

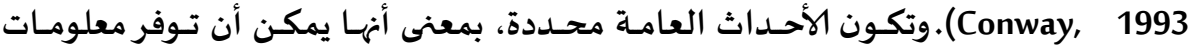

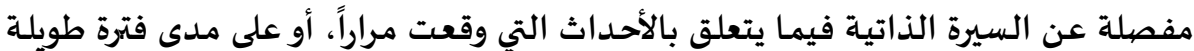

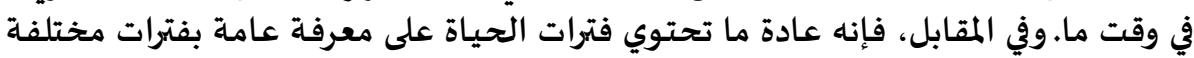

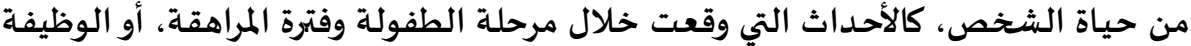

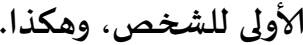

وتعد المعرفة بتفاصيل حادثة ما المستوى الأكثر تحديداً من ذاكرة السيرة الذاتية،

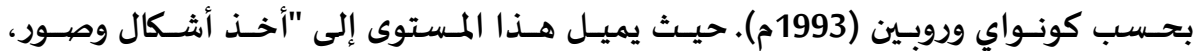

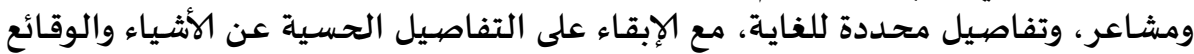

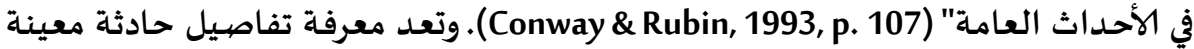

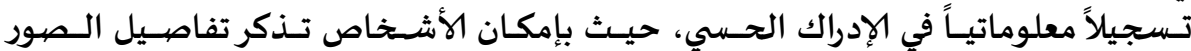

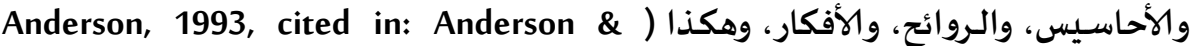

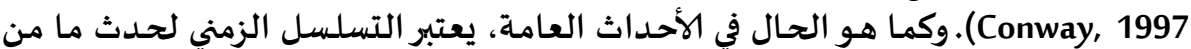

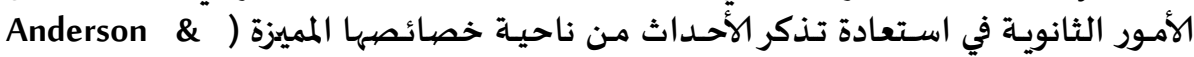

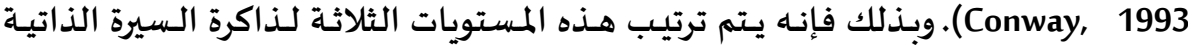

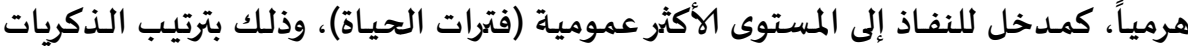

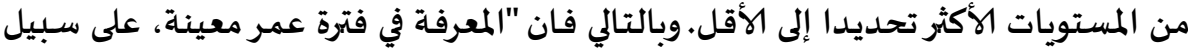

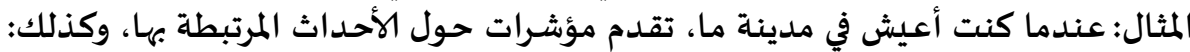




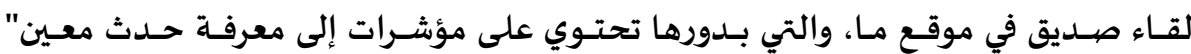

.(Conway and Rubin, 1993, p. 109)

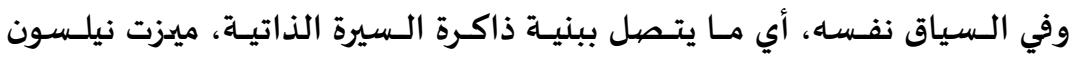

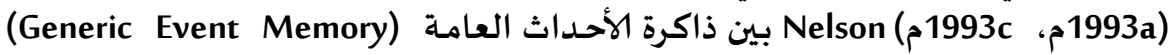

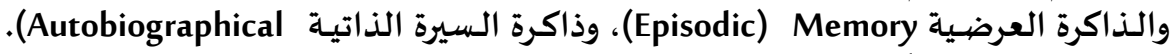

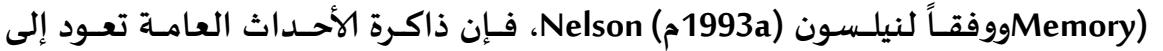

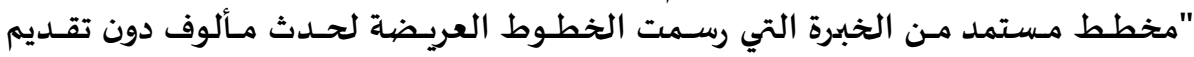

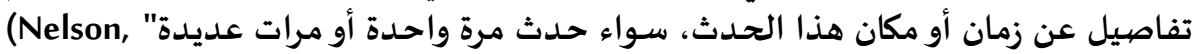
ذاكرة1993a, p. 7)

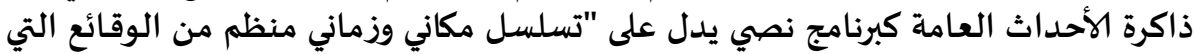

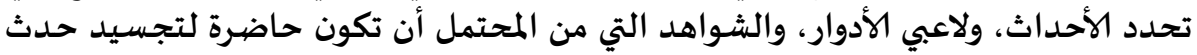

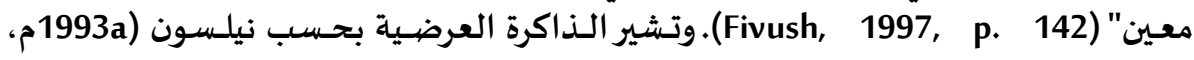

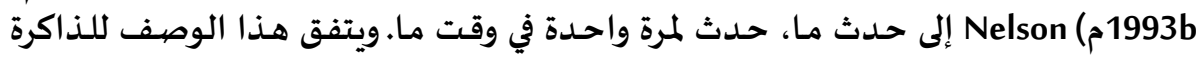

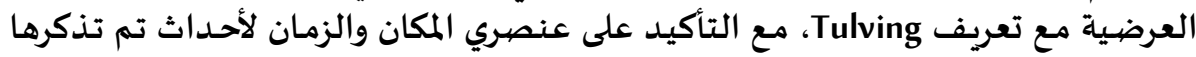

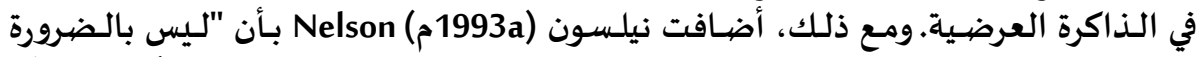

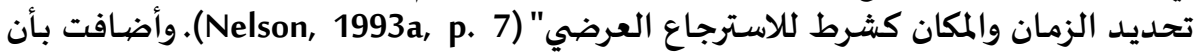

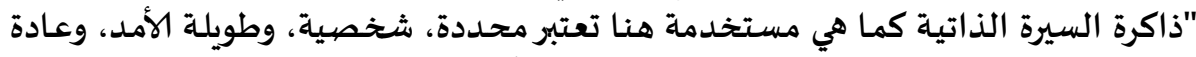

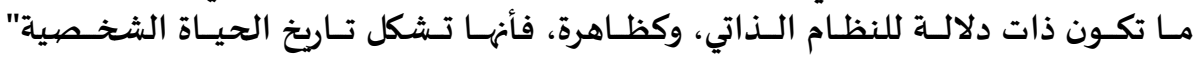

(Nelson, 1993a, p. 8)

وهكذا، ترى نيلسون، بأن ليس كل الذكريات العرضية تصبح ذكريات سيرة ذاتية،

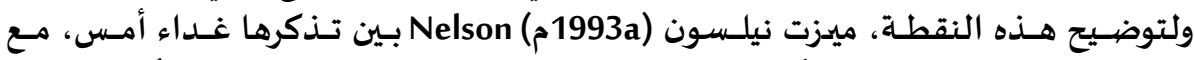

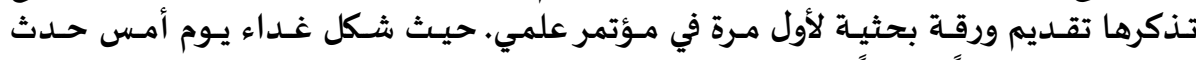

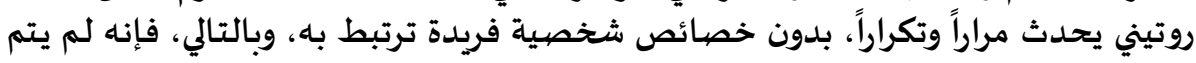

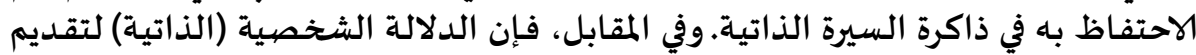

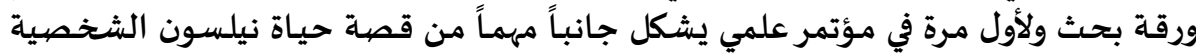

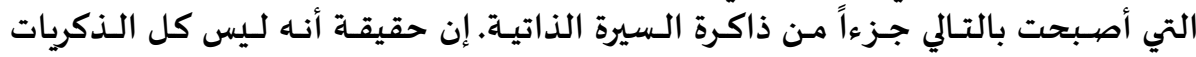

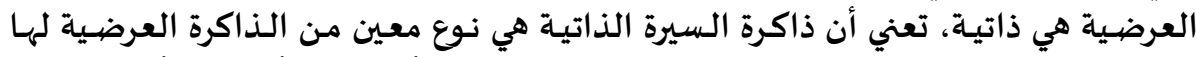

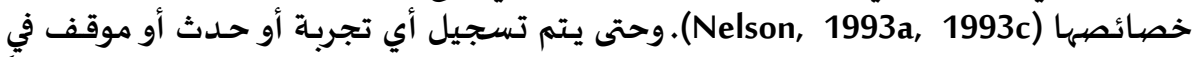

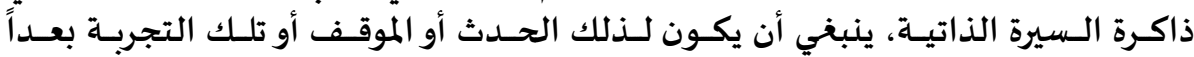

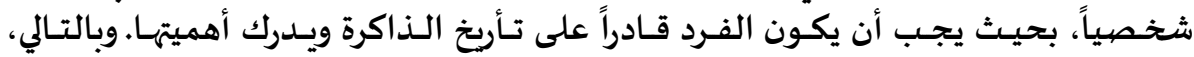

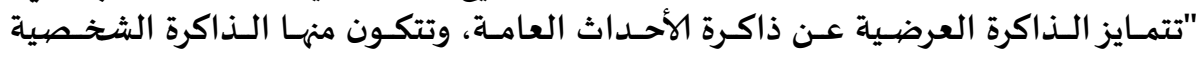

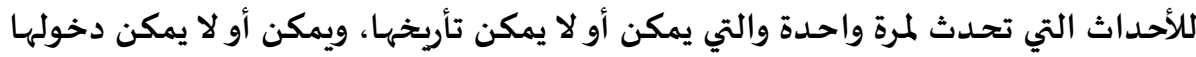

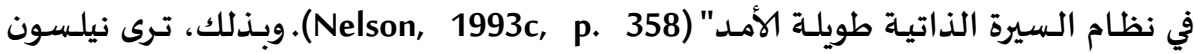

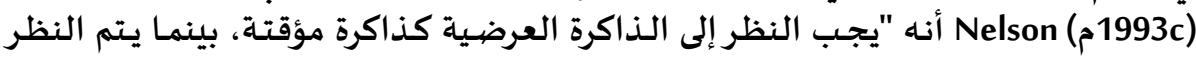

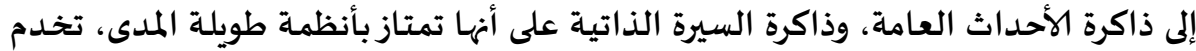

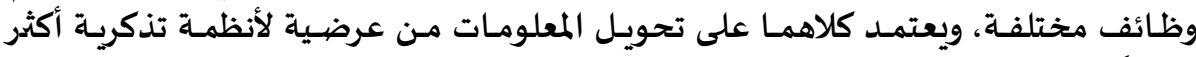

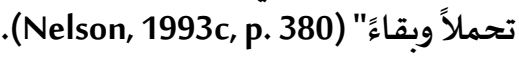




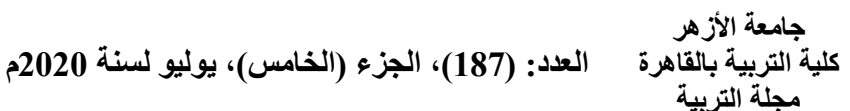

هـذا الوصـف يشير إلى أن أي تجربـة (موقـف أوحسدث) تحفظظ بدايـة في الـذاكرة

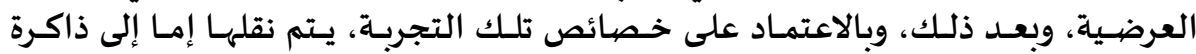

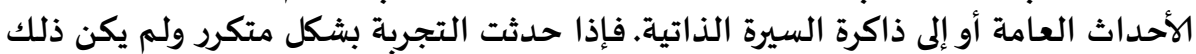

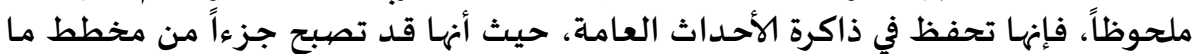

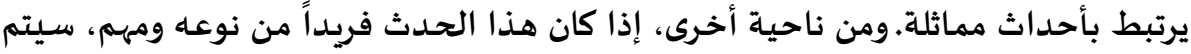
تسجيله في ذاكرة السيرة الذاتية.

$$
\text { نمو ذاكرة السيرة الذاتية: }
$$

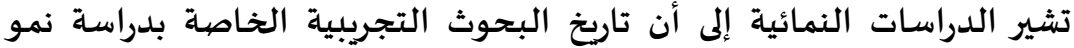

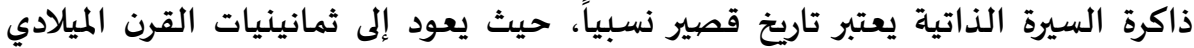

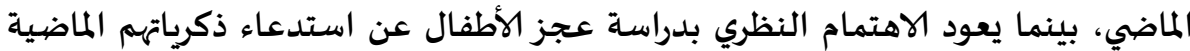

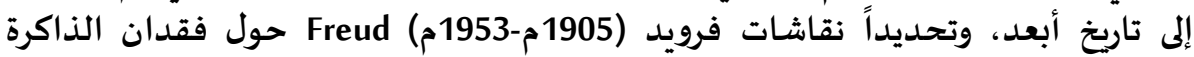

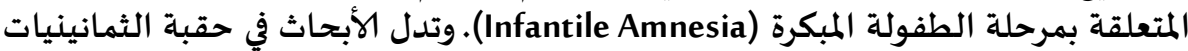

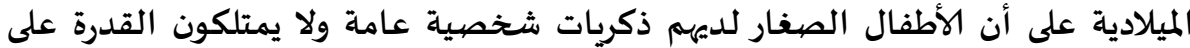

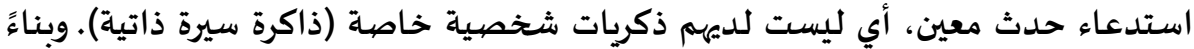

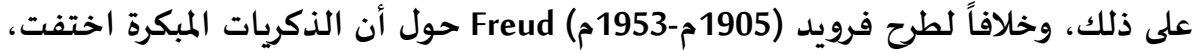

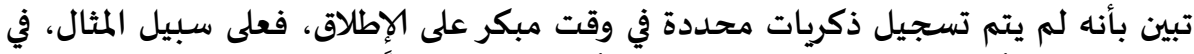

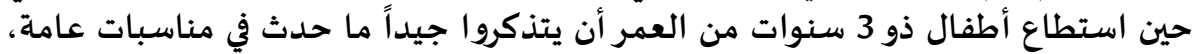

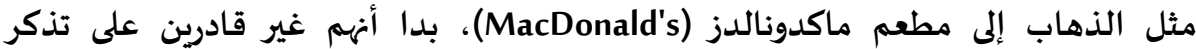

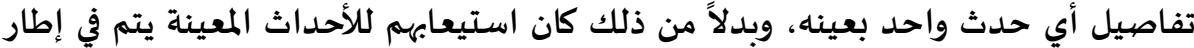

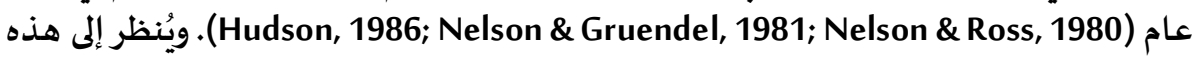

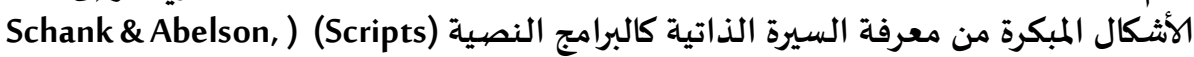

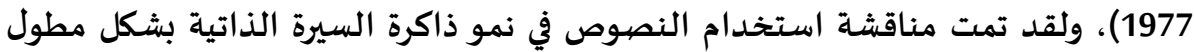
من قبل نيلسون في أعمالها البحثية (على سبيل المثئ المثال: (Nelson, 1993a, 1993b, 1993c).

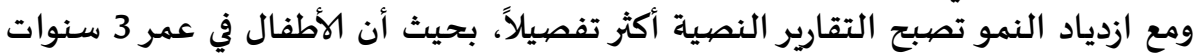

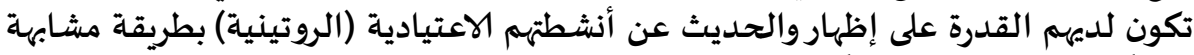

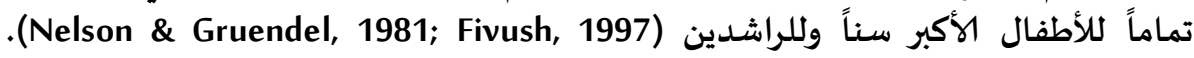

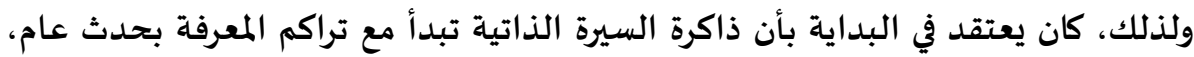

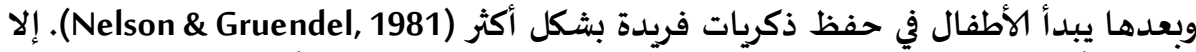

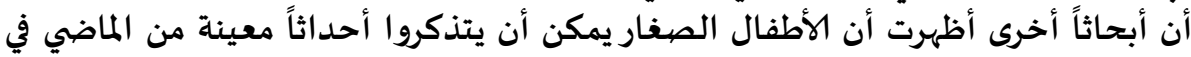

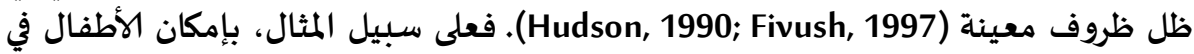

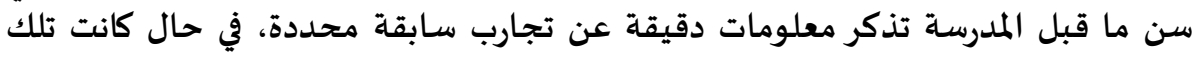

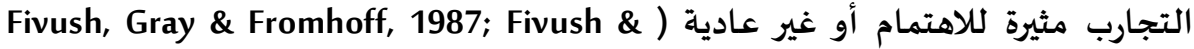

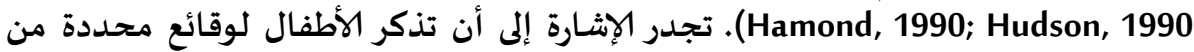

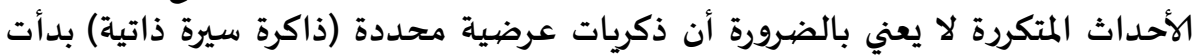

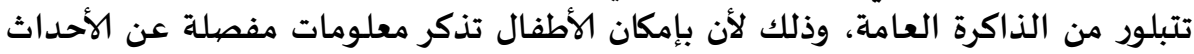
المحددة التي واجهوها مرة واحدة فقط الذب (Hudson \& Nelson, 1986; Hudson, 1990). 


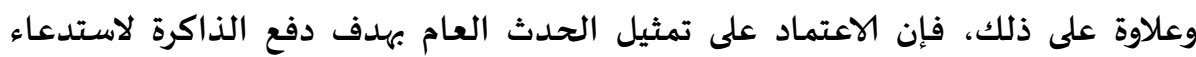

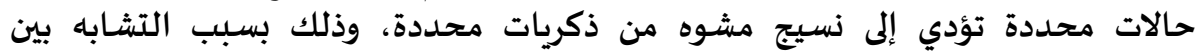

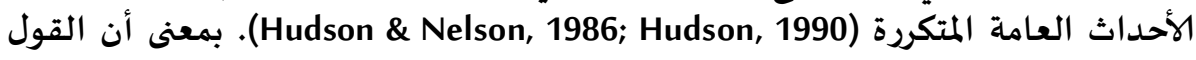

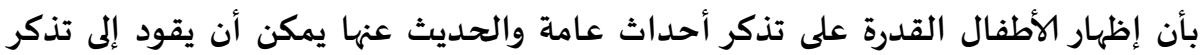

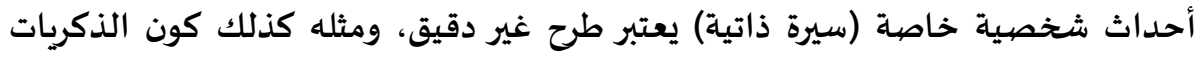

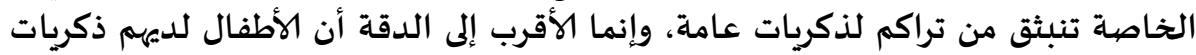
خاصة لتجارب مثيرة للاهتمام ومتميزة في حياتهم.

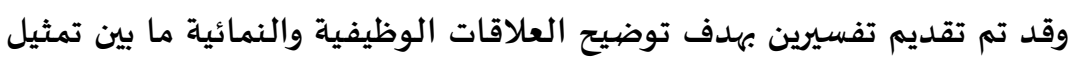

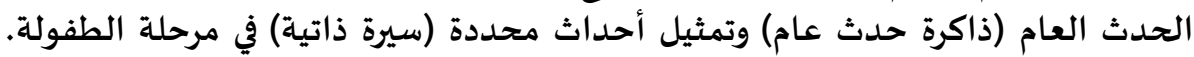

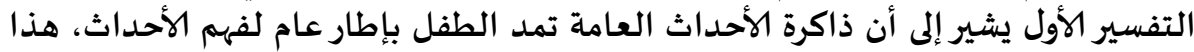

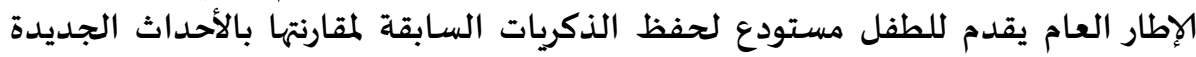

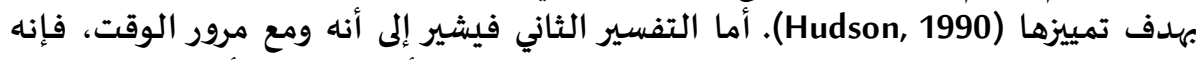

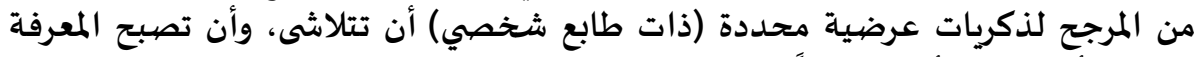

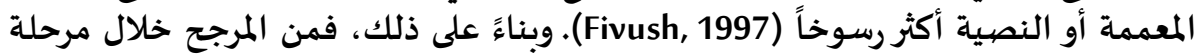

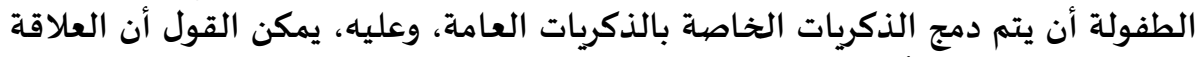

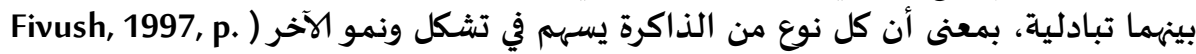

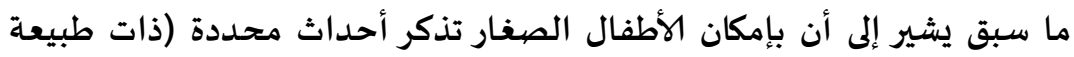

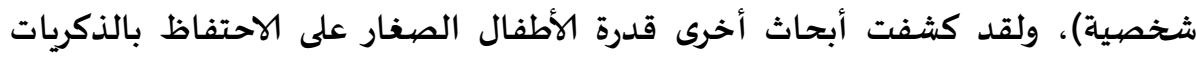

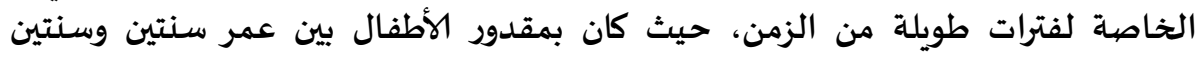

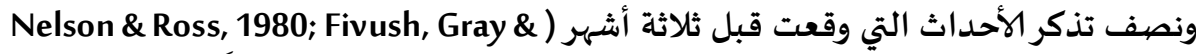

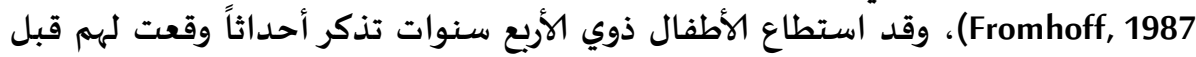

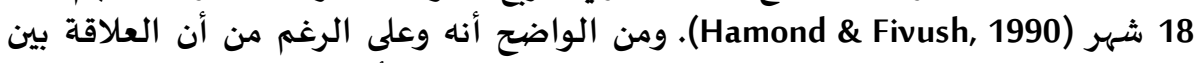

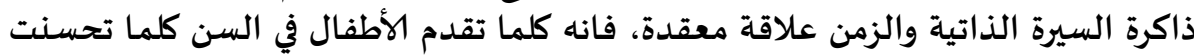

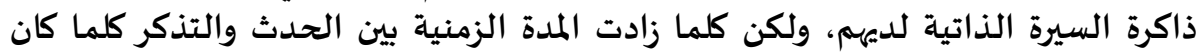

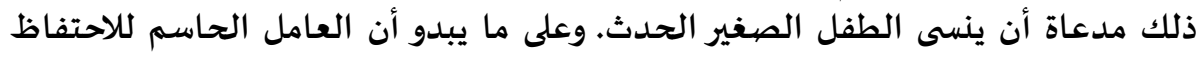

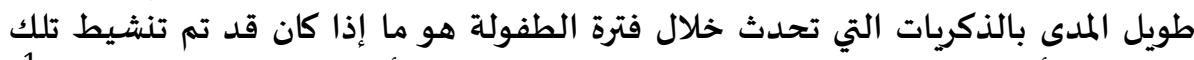

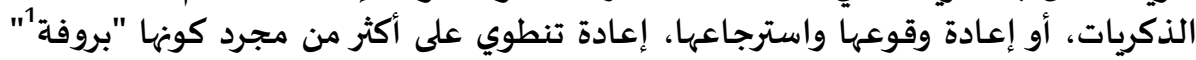
(Rehearsal)

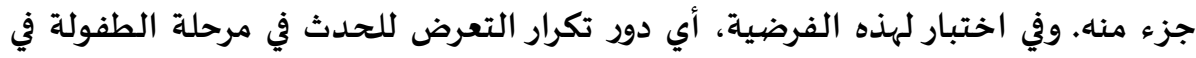

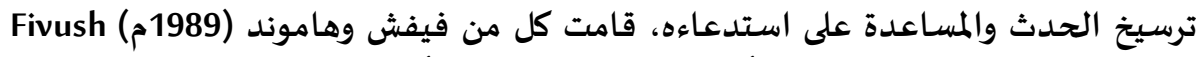
and Hamond

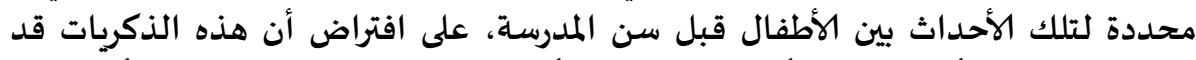

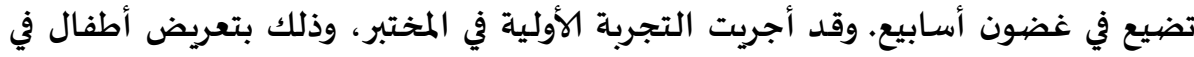

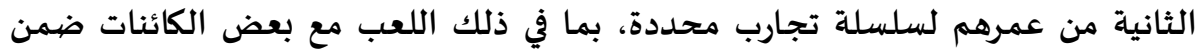

1 1 إحدى استراتيجيات التذكر التي تقوم على الترديد اللفظي للمادة المراد تذكرها بهاف الاحتفاظ بها، أو إعادة رواية الحدث بهلف عدم نسيانه. 


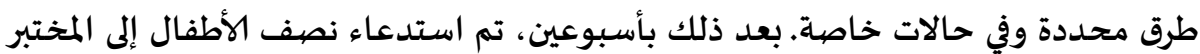

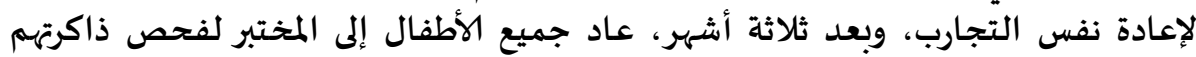

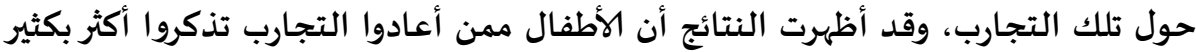

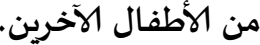

وبذلك يمكن القول أن إعادة تعريض الطفل الصغير لتجربة سابقة يساعد في

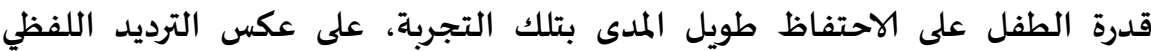

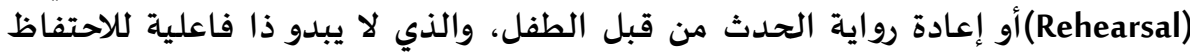

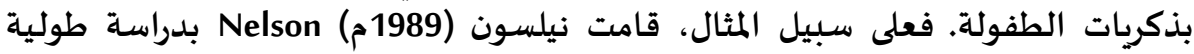

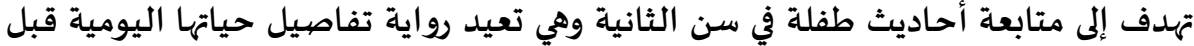

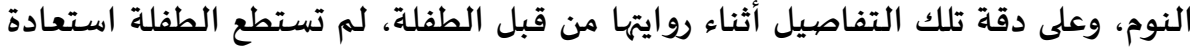

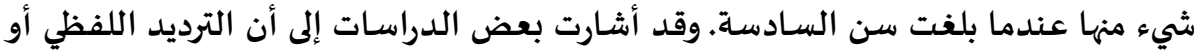

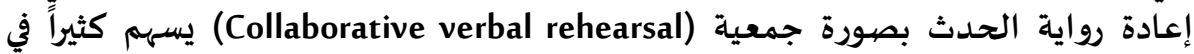

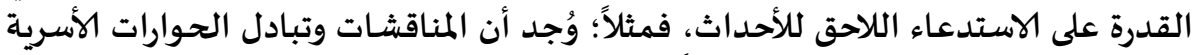

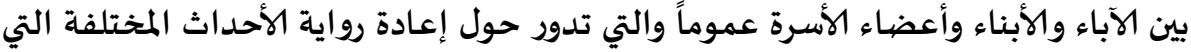

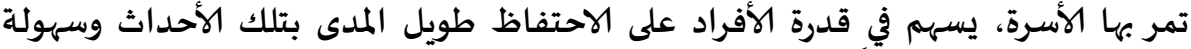

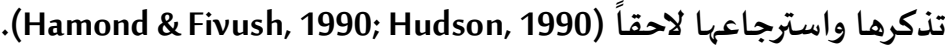

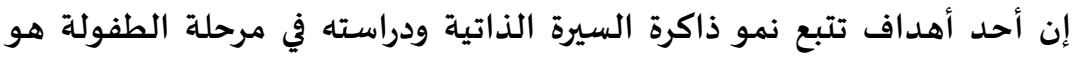

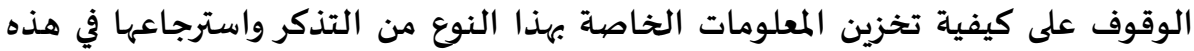

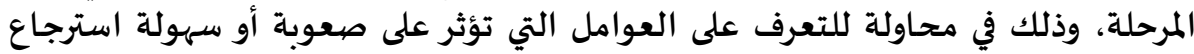
تلك الذكريات في مراحل العمر اللاحقة.

الفروق الفردية والجمعية في ذاكرة السيرة الذاتية:

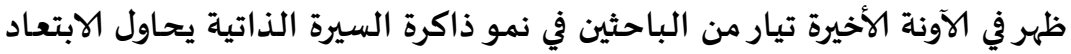

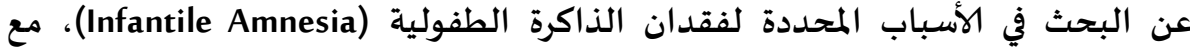

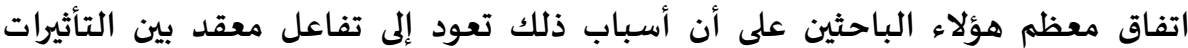

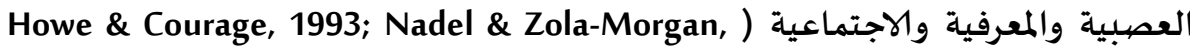
1984; Perner \& Ruffman, 1995; Pillemer, 1998, Pillemer \& White, 1989

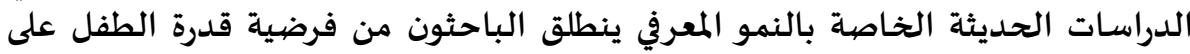

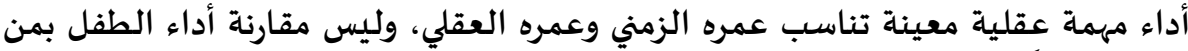

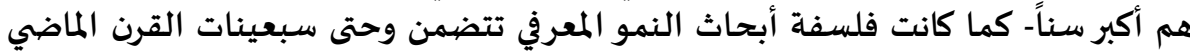

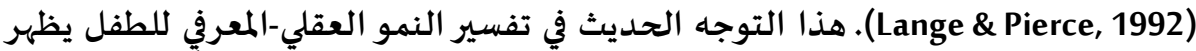

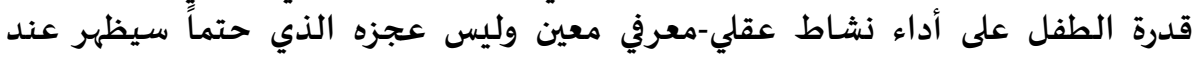

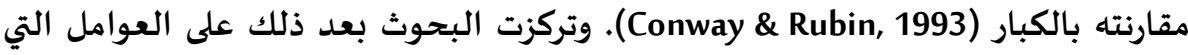

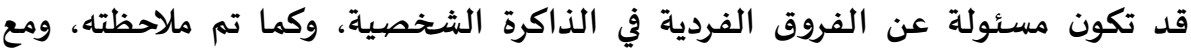

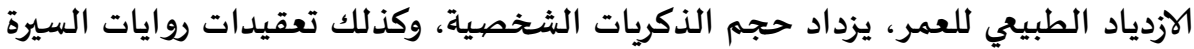
الذاتية، وتبرز كذلك الفروق الفردية وبدرجة كبيرة في تذكر أحداث وموات الثراقف السية السيرة الذاتية 
Fivush, Haden \& Adam 1995; Fivush, ) الشخصية للأفراد عبر المجتمعات المختلفة الموارية الاساس 1998

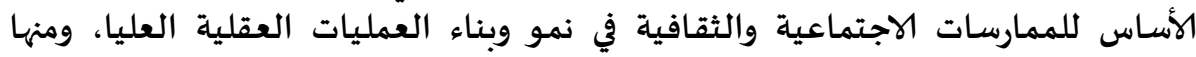

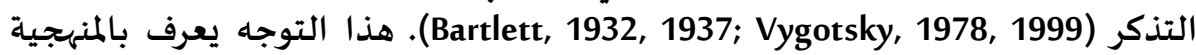

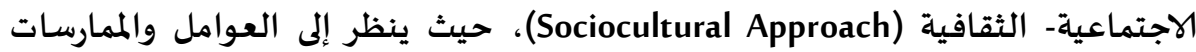

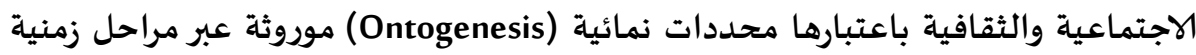

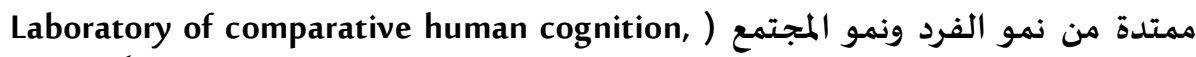

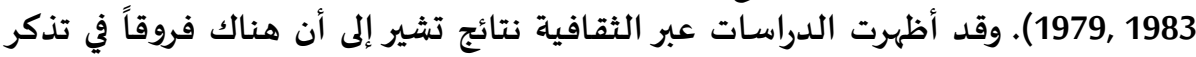

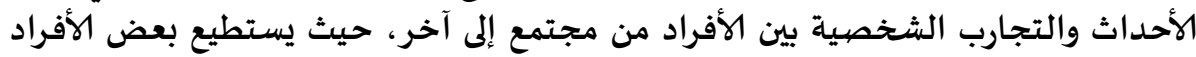

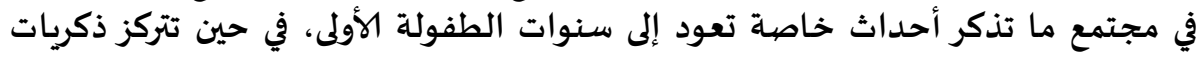

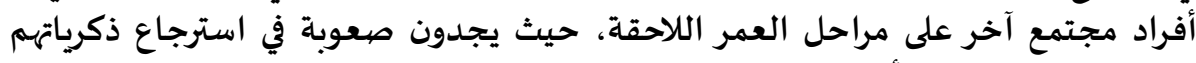

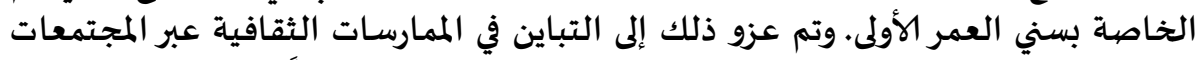

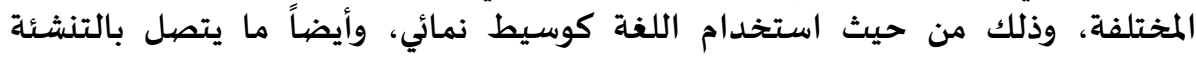

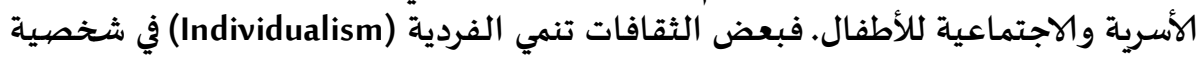

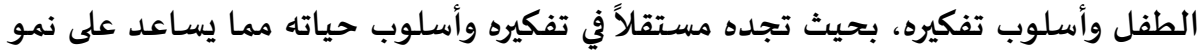

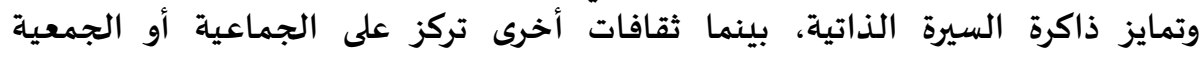
(Collectivism)

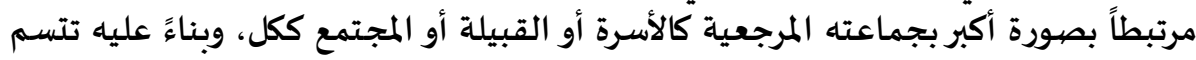

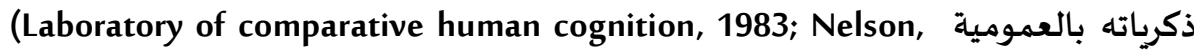

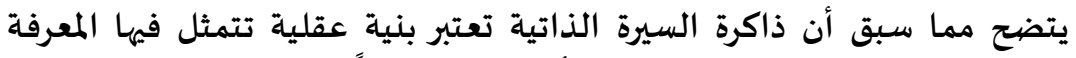

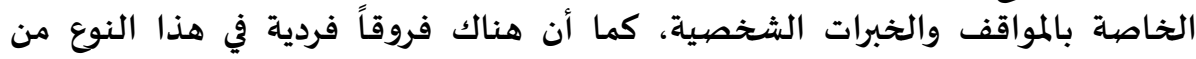

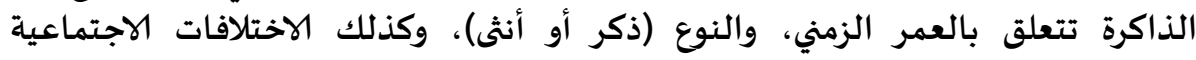

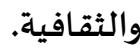

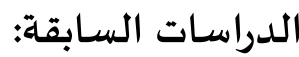

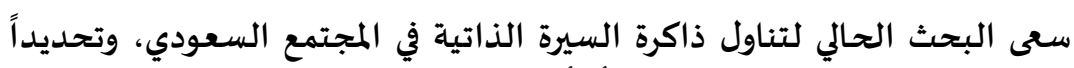

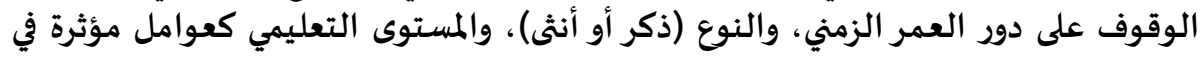

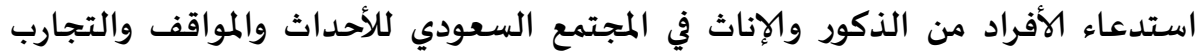

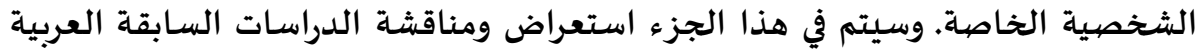
والأجنبية التي عنيت ببحث تأثير هذه المتغيرات على ذاكرة السيرة النيت الذاتية.

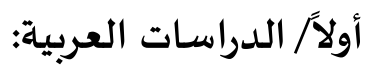

موضوع ذاكرة السيرة الذاتية لم يطرق كثيراً في الأبحاث والأدبيات النفسية النداثية

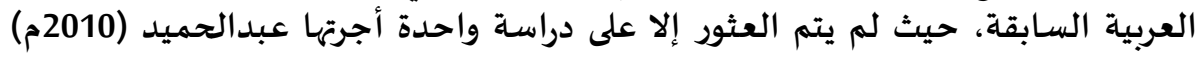

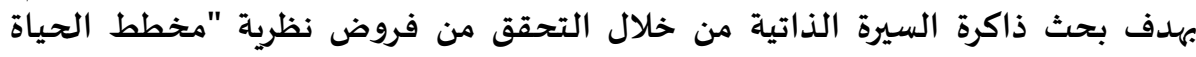

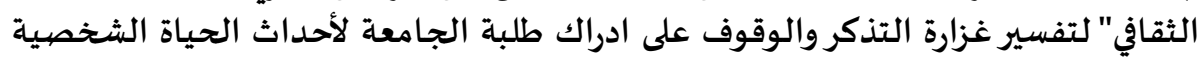

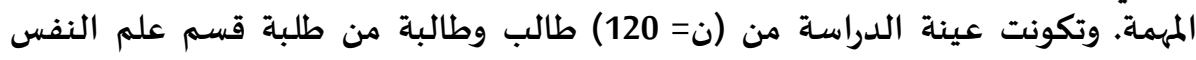


بجامعة سوهاج بجمهورية مصر العربية، بحيث يمثل الطلاب الذكور (32) طالباً بمتوسط إنبا

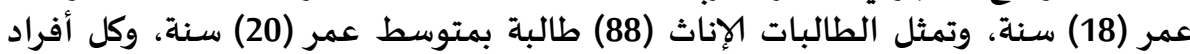

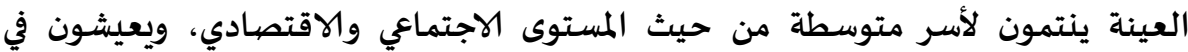

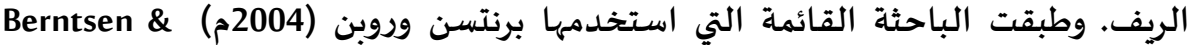
Rubin

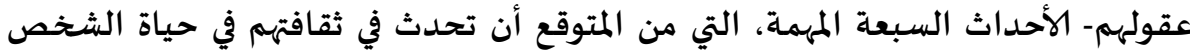

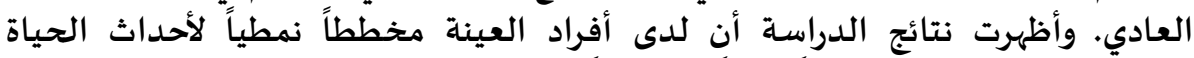

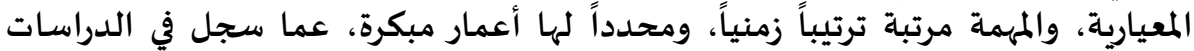

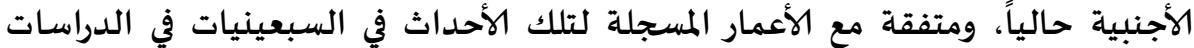

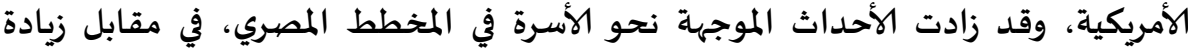
أحداث توكيد استقلالية وفردية المراهق في المخطط المادية الأجنبي.

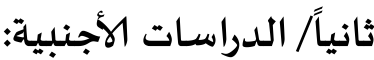

قامت لاتشتي وسوتن (2018م) Luchetti \& Sutin بدراسة تهدف إلى معرفة تأثير

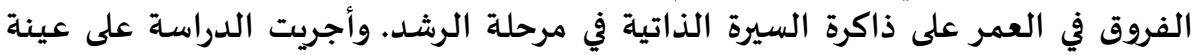

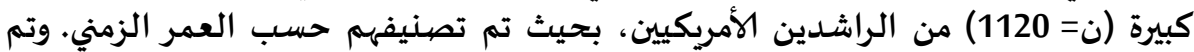

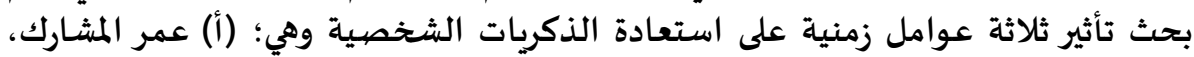

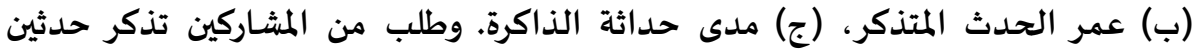

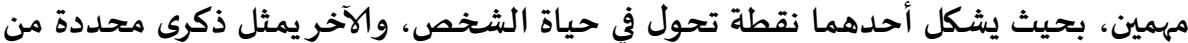

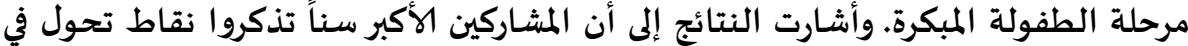

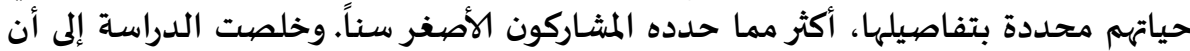

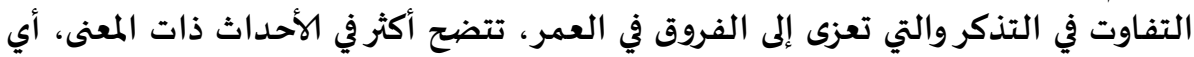
التي تمثل أهمية لدى الشخص.

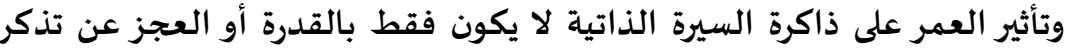

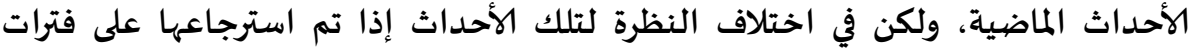

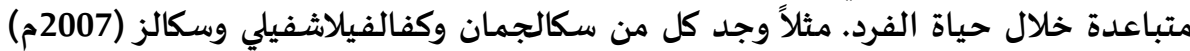
فرد تراو أ Schlagman, Kvavilashvili, \& Schulz

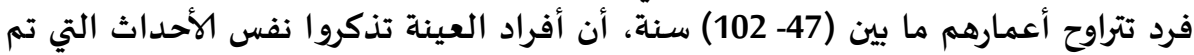

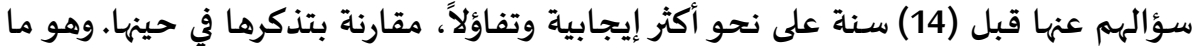

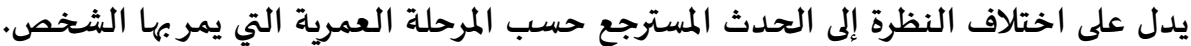

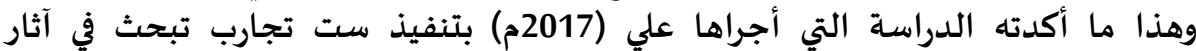

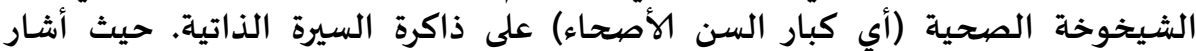

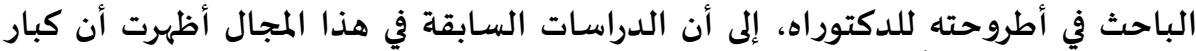

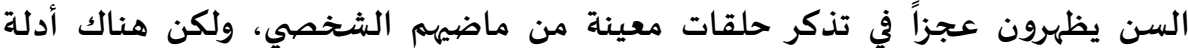

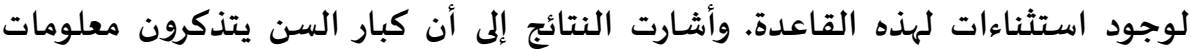

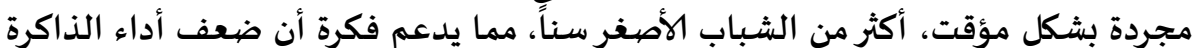


لدى كبار السن يرتبط بتمثيل الذاكرة المتغير عبر الزمن، بدلاً من عمليات الاسترداد

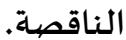

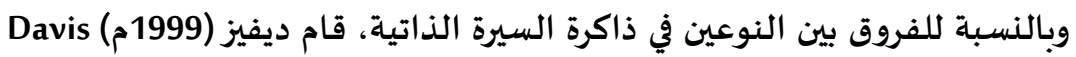

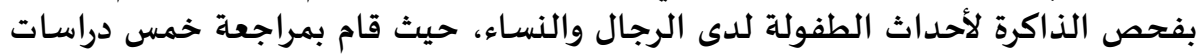

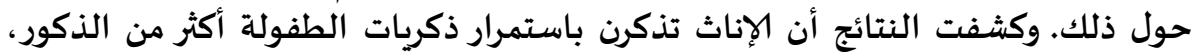

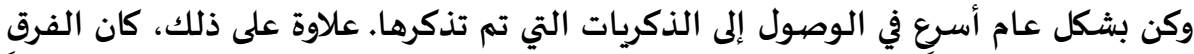

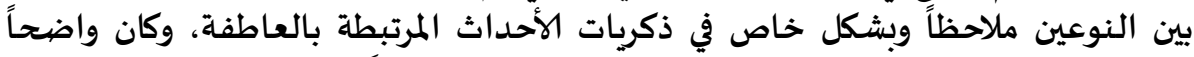

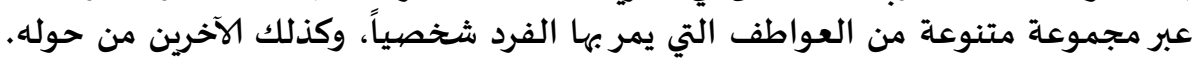

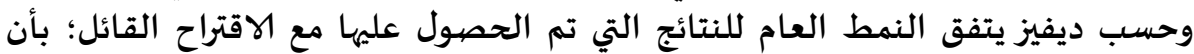

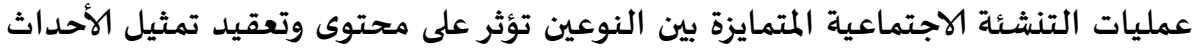

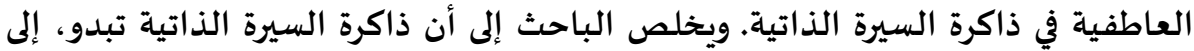
حد ما، ظاهرة ذات أساس اجتماعي.

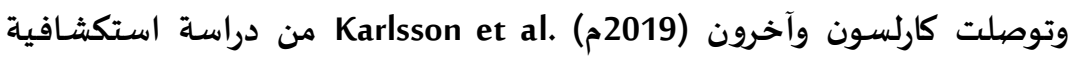

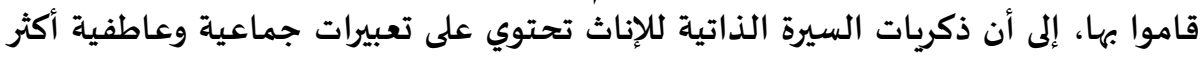

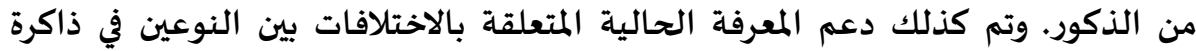

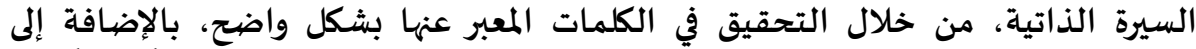

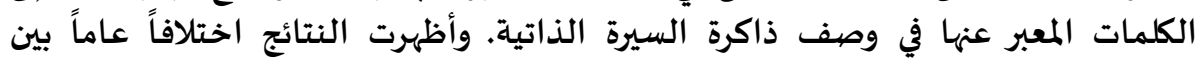

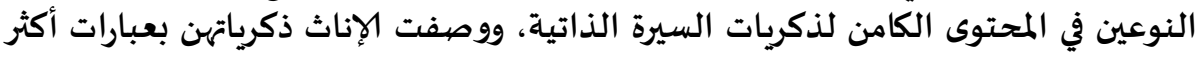

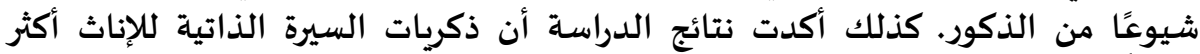
توجهاً نحو المجتمع من ذكريات السيرة الذاتية لدى الذكورات الذكور.

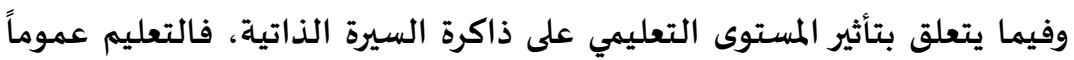

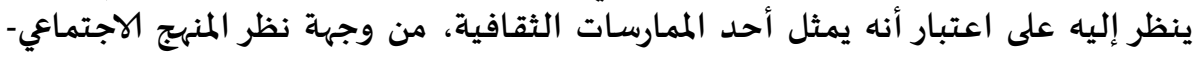

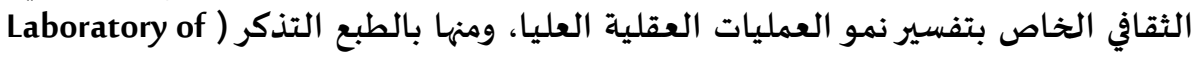

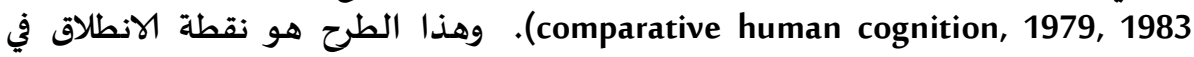

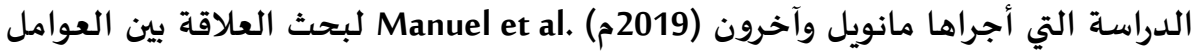

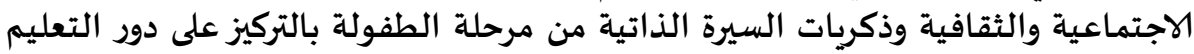

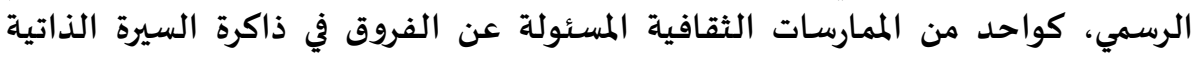

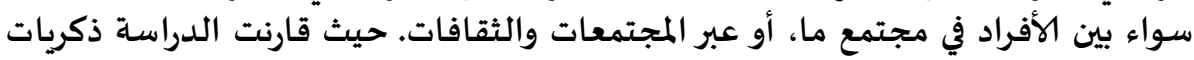

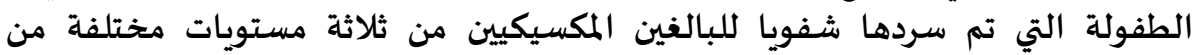

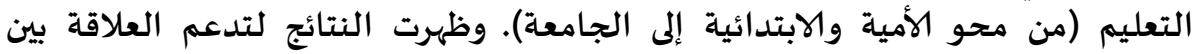

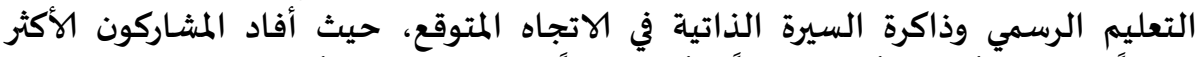

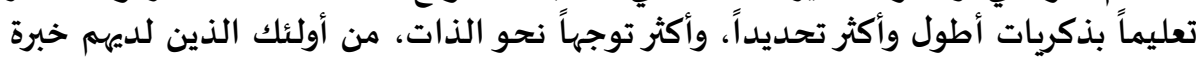

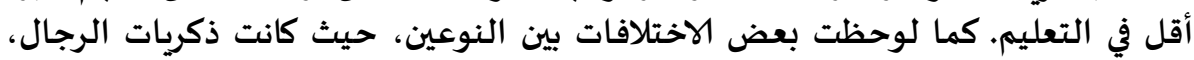

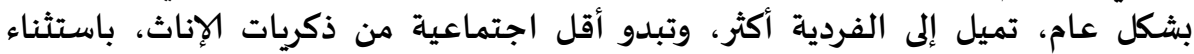

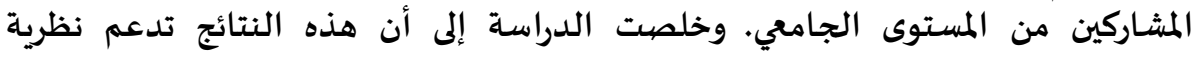

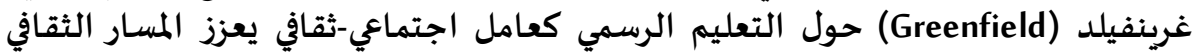

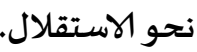




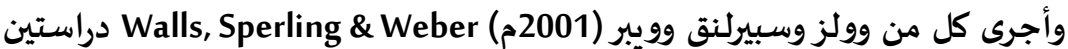

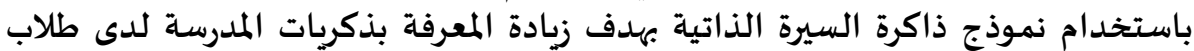

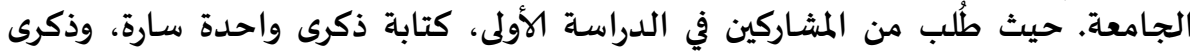

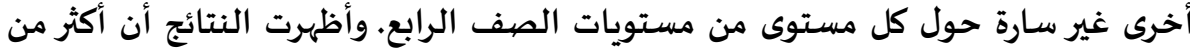

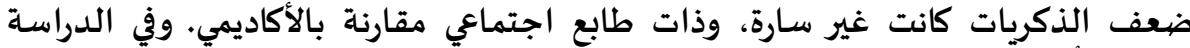

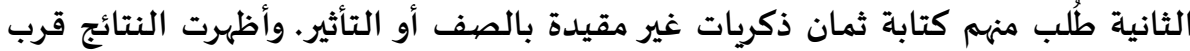

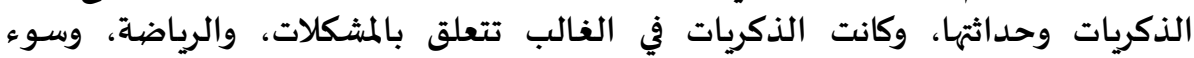

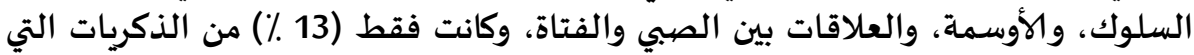

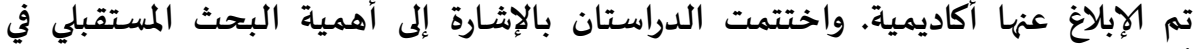

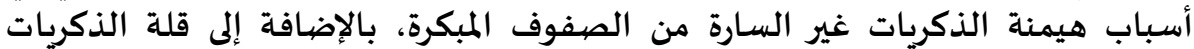

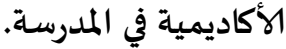
التعليق على الدراسات السـابقة:

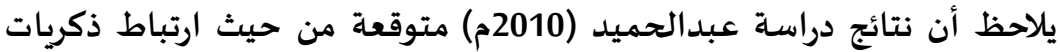

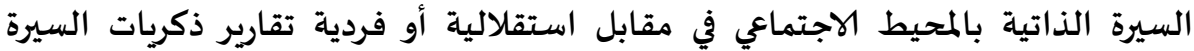

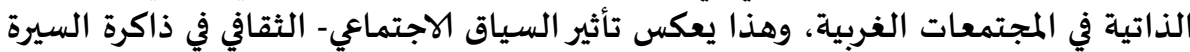

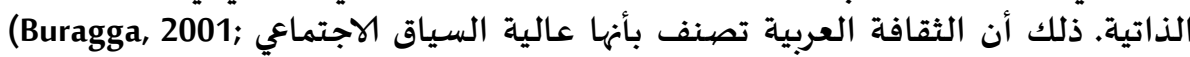

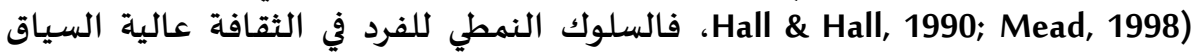

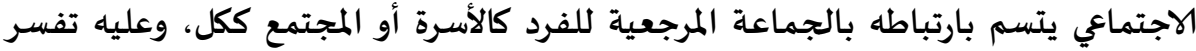
الذكريات بأهها تميل إلى الجمعية أكثر من الفردية (Fivush \& Nelson, 2004).

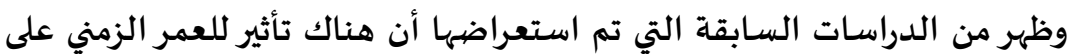

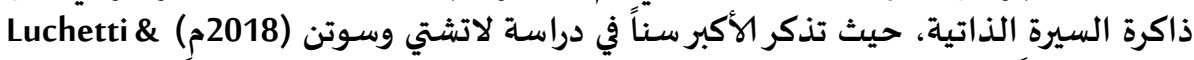

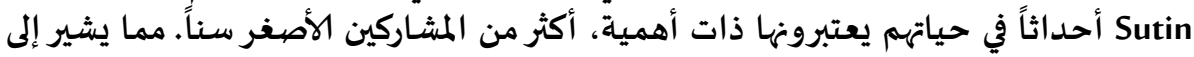

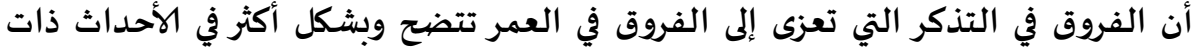

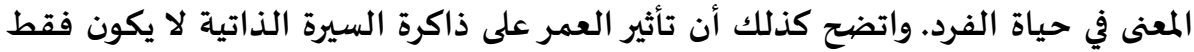

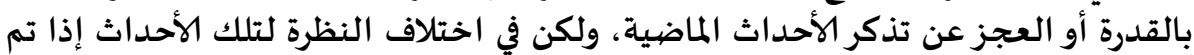

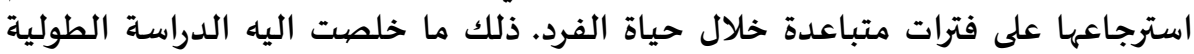

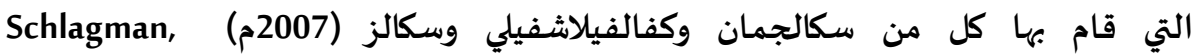
Kvavilashvili, \& Schulz

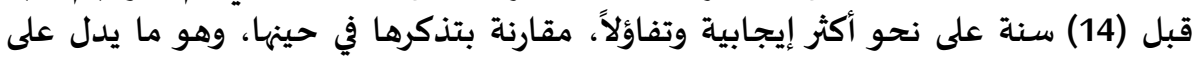

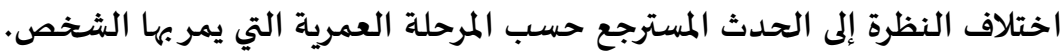

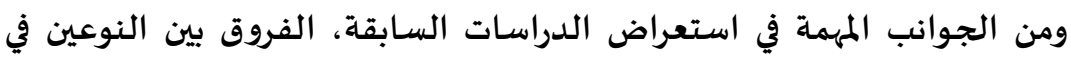

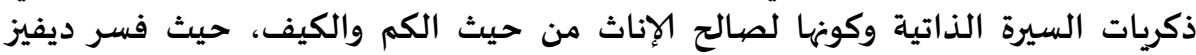

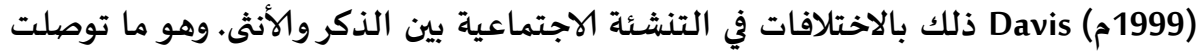

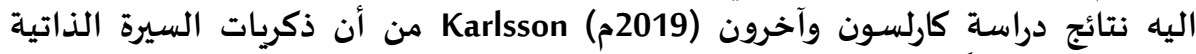

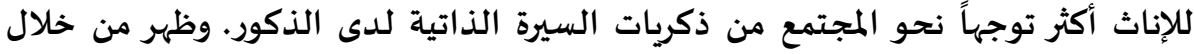




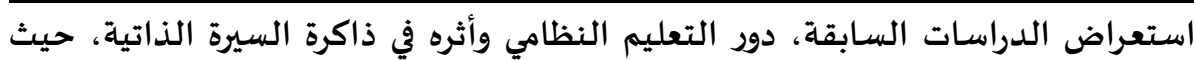

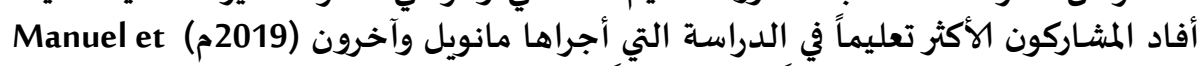
في al.

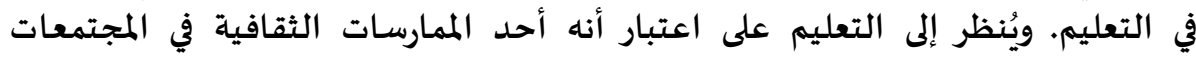

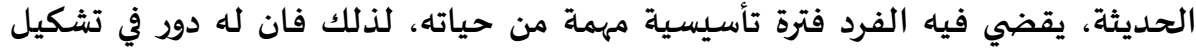

ذكريات السيرة الذاتية وصياغتها (Walls, Sperling \& Weber, 2001).

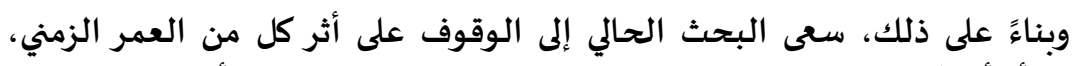

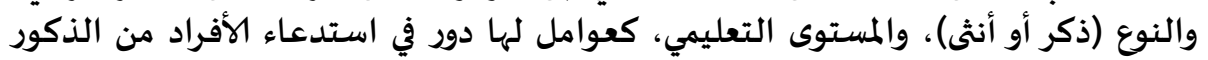

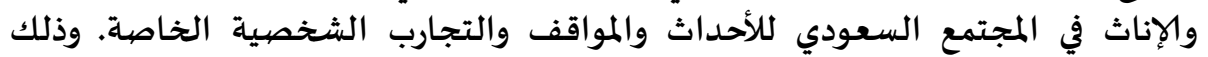

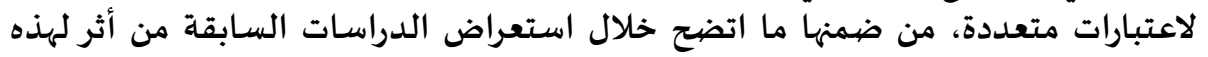

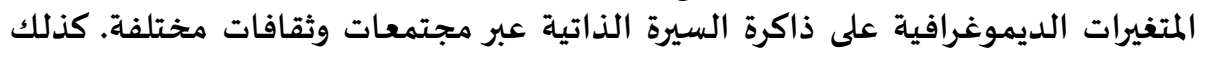

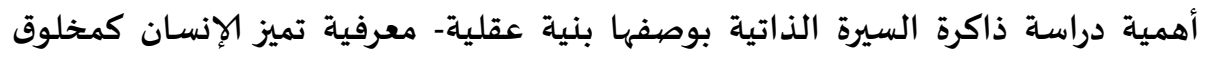

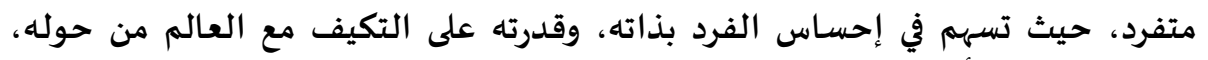

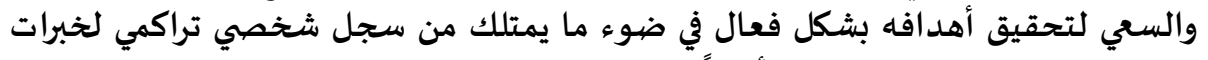

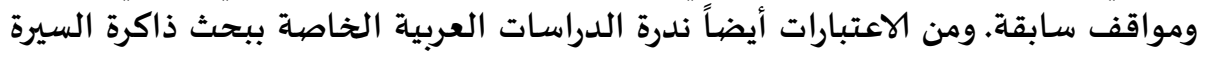

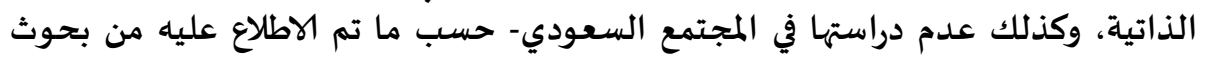

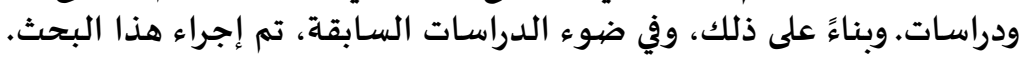

فروض البحث: في ضوء ما تم عرضيه من إطار نظري ودراسات سابقة أمكن صياغة

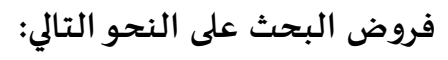

1. توجد علاقة دالة إحصائياً بين العمر الحالي وعمر التذكر لدى المشاركين في البحث.

2. توجد فروق دالة إحصبائيا بين الذكور والإناث في متوسط عمر التذكر.

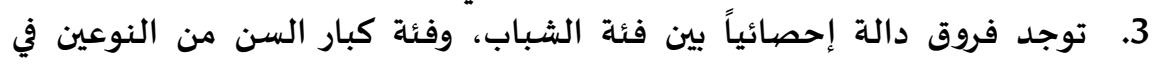
متوسط عمر التذكر. 4. يعتبر المستوى التعليمي محددراً للتذكر. 5. يوجد مستوى مرتفع من ذكريات السيرة الذاتية لدى المشاركين في البحث.

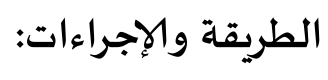

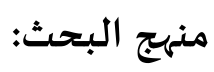

تم استخدام المنهج الوصفي لملاءمته لطبيعة هذا البحث.

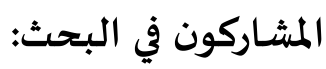

تكون حجم المشاركين في البحث من (ن= 126) فرداً من النوعين، تم اختيارهم

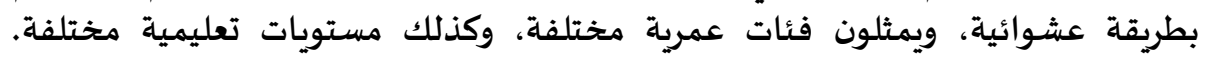

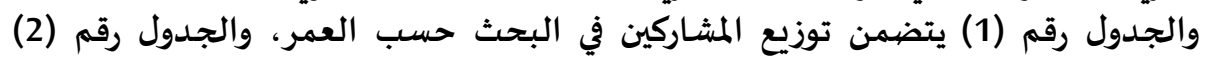
يوضح توزيع المشاركين في البحث حسب مستوياتهم التعليمية. 


$$
\text { كلية جامتربة الأزقاهرة العدد: (187)، الجزء (الخامس)، يوليو لسنة 2020م }
$$

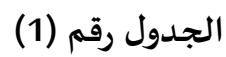

\begin{tabular}{|c|c|c|c|c|c|c|c|c|c|c|c|}
\hline \multicolumn{11}{|c|}{ العمر بالسنوات } & \multirow{3}{*}{ النوع } \\
\hline \multirow{2}{*}{ المتوسط } & النسبة & المححموع & -91 & -81 & -71 & -61 & -51 & -41 & -31 & -15 & \\
\hline & المئوية & المبتموح) & 100 & 90 & 80 & 70 & 60 & 50 & 40 & 30 & \\
\hline 36 & 69 & 87 & 1 & 1 & 1 & 3 & 11 & 5 & 20 & 45 & ذكر \\
\hline 34.94 & 31 & 39 & 0 & 0 & 0 & 1 & 2 & 10 & 10 & 16 & أنثى \\
\hline 35.67 & 100 & 126 & 1 & 1 & 1 & 4 & 13 & 15 & 30 & 61 & المجمموع \\
\hline
\end{tabular}

توزيع المشاركين في البحث حسب العمر

يتضح من الجدول رقم (1)، أن الإناث شكلن ما نسبته (31 \%) من المشاركاركين في

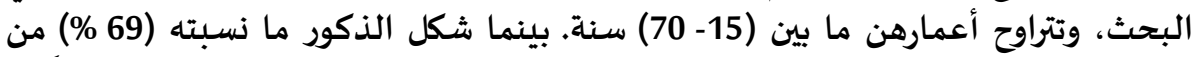

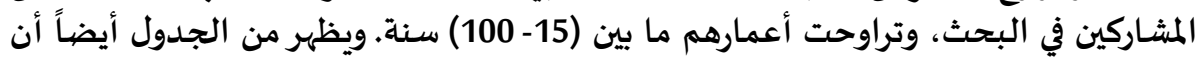

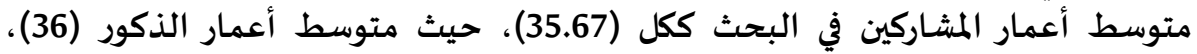

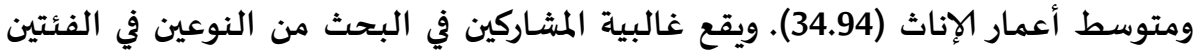

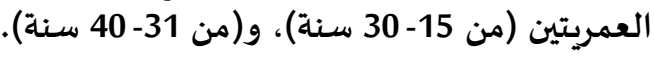

\begin{tabular}{|c|c|c|c|c|c|c|c|c|c|c|}
\hline \multicolumn{10}{|c|}{ المستوى التعليمي } & \multirow{2}{*}{ النوع } \\
\hline المجموع & الدكتوراه & |لماجستير| & لجامعية| & لدبلوم| & الثانوية & المتوسطة & |الابتدائية & والكتابة & |الأمية & \\
\hline 92 & 3 & 9 & 30 & 5 & 29 & 8 & 5 & 1 & 3 & ذكر \\
\hline 34 & 0 & 1 & 11 & 3 & 4 & 5 & 2 & 1 & 6 & أنثى \\
\hline 126 & 3 & 10 & 41 & 8 & 33 & 13 & 7 & 2 & 9 & المجموع \\
\hline
\end{tabular}
الجدول رقم (2)

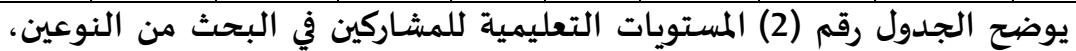

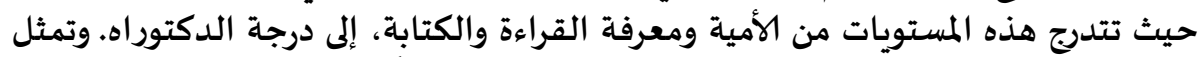
الشهادة الثانوية والجامعية المستويات التعليمية الأكثر شيوعاً لدى المشاركين الماتية في البحث.

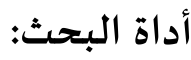

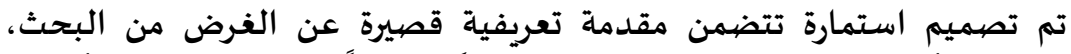

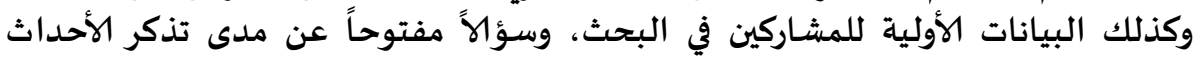


والمواقف الشخصية في حياة المفحوص كلها، بمعنى إلى أي عمر يمكنه تذكر وتحديد موقف

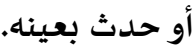

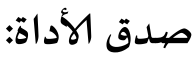

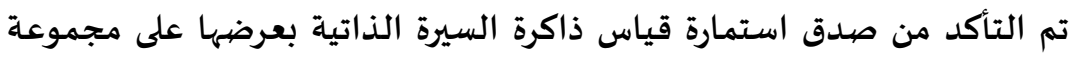

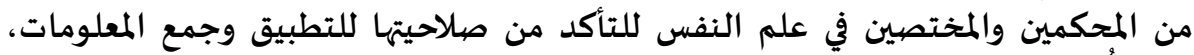
حيث أُخذ بملاحظات المحكمين وتعدين علميلاتهم.

ثبات الأداة:

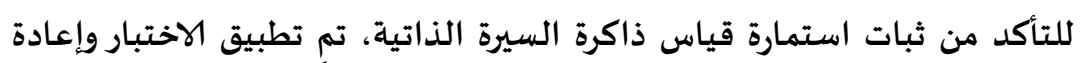

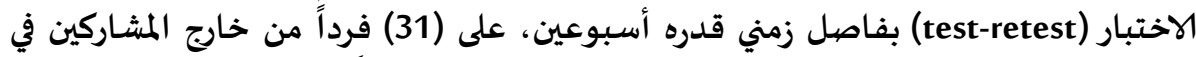

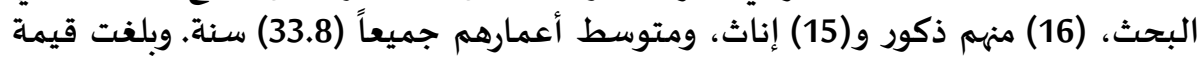

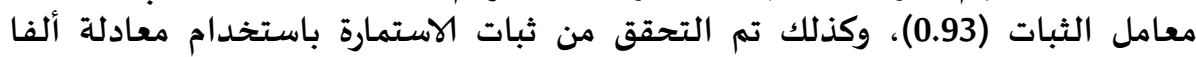

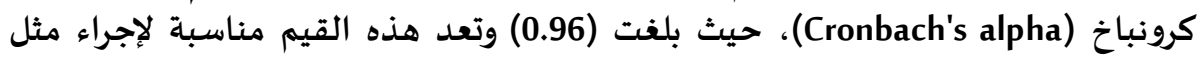

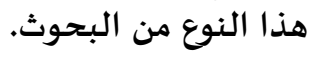

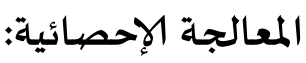

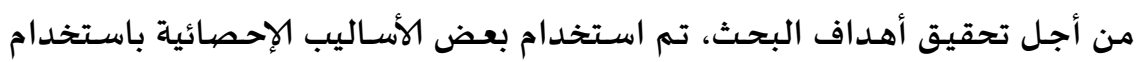

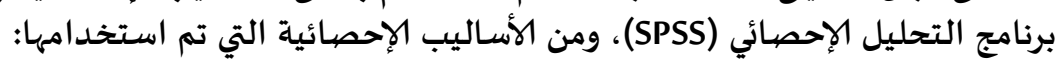
المتوسطات الحسابية، والانحرافات المعيارية، والنسب المئوية.

معامل الارتباط بيرسون (Pearson correlation coefficient).

• • • • معامل ألفا كرونباخ (Cronbach's alpha).

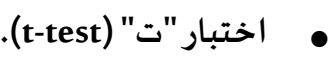

• اختبار تحليل التباين الأحادي (One-way ANOVA).

تحليل المحتوى (Content Analysis) كأسلوب للتحليل الكيفي.

نتائج البحث ومناقشتها:

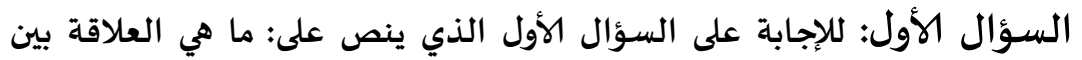

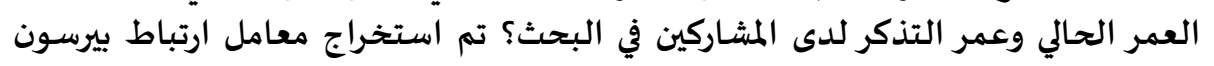

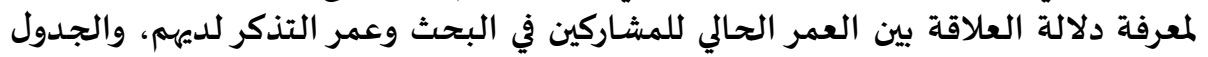
رقم (3)، يوضيح نتيجة ذلك. 


$$
\text { كلية جلتربية الألقاهرة العدد: (187)، الجزء (الخامس)، يوليو لسنة 2020م }
$$

\begin{tabular}{|c|c|c|c|c|c|c|}
\hline الاحصلائية & معامل & المعياري & متوسط التذر & المعياري & متوسط العمر & في البحث \\
\hline علاقة إيجابية & $* * 0.409$ & 1.95 & 5.39 & 14.82 & 35.67 & 126 \\
\hline
\end{tabular}

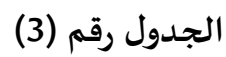

معامل الارتباط بين العمر الحالي وعمر التذكر (ن= 126)

يتضح من الجدول رقم (3) أن هناك علاقة إيجابية ودالة إحصائياً بين العمر

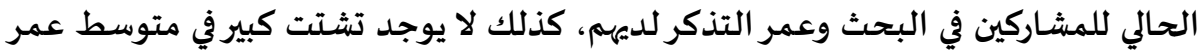

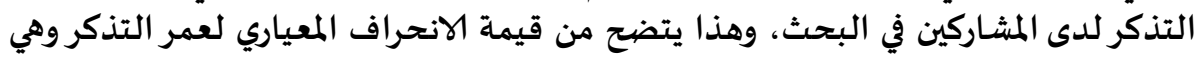

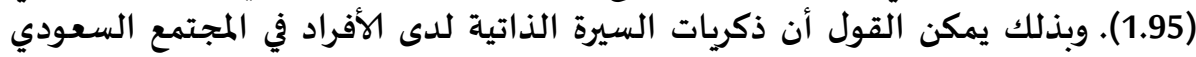

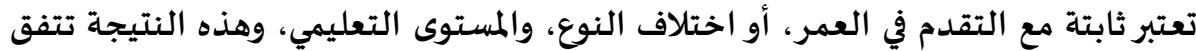

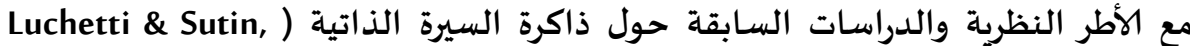

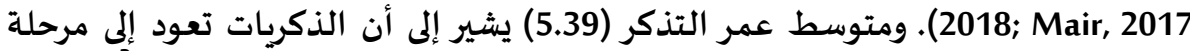

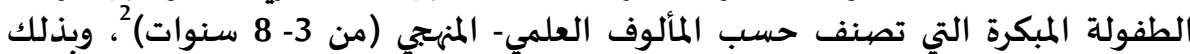

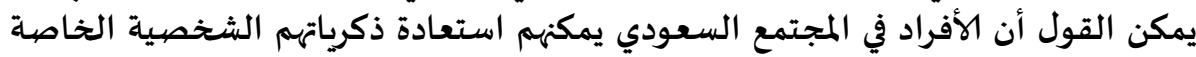
من مرحلة الطفولة المبكرة.

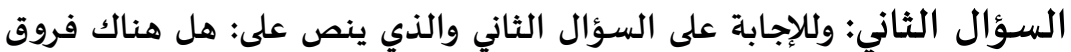

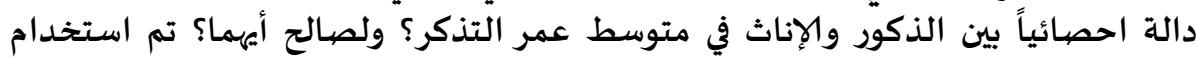

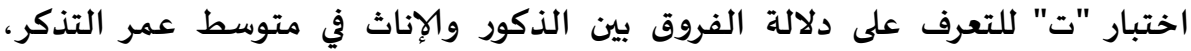
والجدول رقم (4)، يوضح نتيجة ذلك.

نعتبر منظمة الصحة العالية (World Health Organization) مرحلة الطفولة المبكرة من الميلاد إلى ثمان سنوات، بينما في الدراسات النفسية تعتبر الطفولة المبكرة من 3- 8 سنوات، على اعتبار أن المرحلة من الميلاد إلى سنتين هي مرحلة الرضاعة الريات 
الجدول رقم (4) - (4)

المتوسطات الحسابية والانحرافات المعياربة وقيمة "ت"، للفروق بين الذكور والإناث من

المشاركين في البحث تبعاً لمتغير عمر التذكر (ن= 126 المعيارية

\begin{tabular}{|c|c|c|c|c|c|c|c|}
\hline الإحصيائية الدلالة & "ت" قيمة & الإحصائية الدلالة & ليفينة & المعياري & الحستوسط & العدد & النوع \\
\hline \multirow{2}{*}{$* * 0.01$} & \multirow{2}{*}{2.55} & \multirow{2}{*}{0.03} & \multirow{2}{*}{4.60} & 1.85 & 5.47 & 87 & ذكر \\
\hline & & & & 1.46 & 4.62 & 39 & أنثى \\
\hline
\end{tabular}

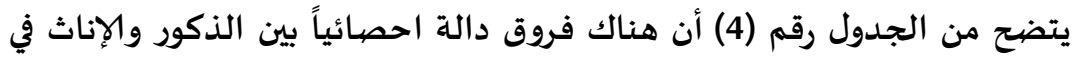

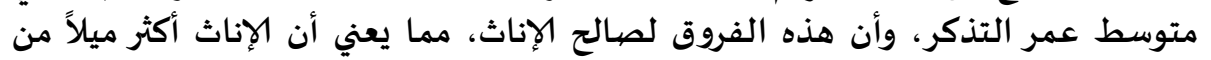

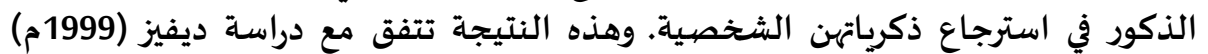

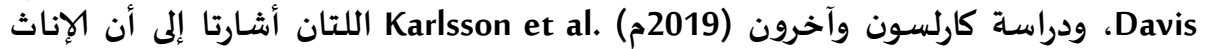

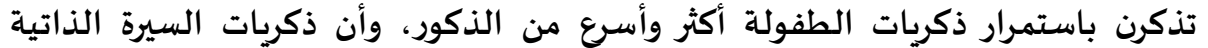

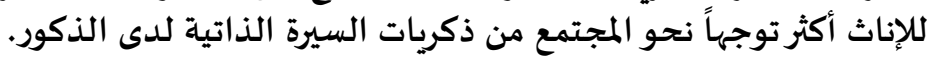

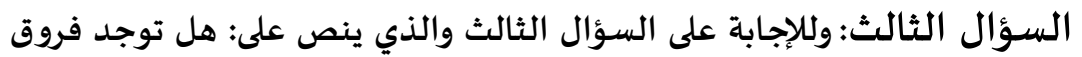

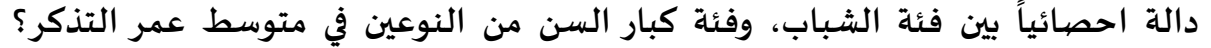

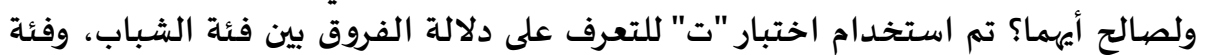

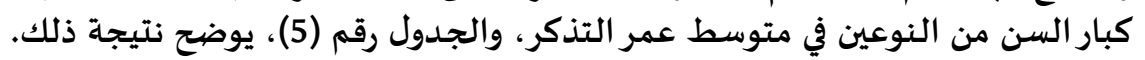

الجدول رقم (5)

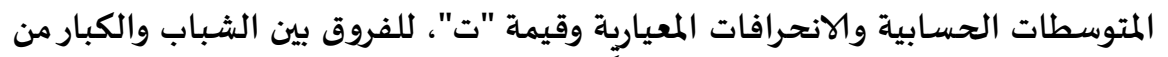
المشاركين في البحث تبعاً لمتغير عمر التذكر (ن= 126 المعيمة )

\begin{tabular}{|c|c|c|c|c|c|c|c|}
\hline الإحصيائية & "ق قيمة & الإحصائية الدلالة & ليفين & المعياري & الحستابي العمر & العدد & النوع \\
\hline \multirow{2}{*}{$* * 0.005$} & \multirow{2}{*}{2.84} & \multirow{2}{*}{0.03} & \multirow{2}{*}{5.10} & 1.60 & 5.00 & 103 & فئة الشباب \\
\hline & & & & 2.22 & 6.13 & 23 & الكبئة \\
\hline
\end{tabular}

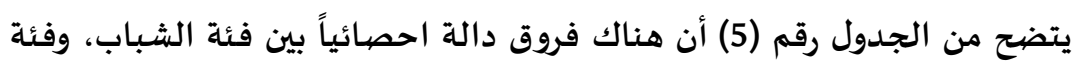

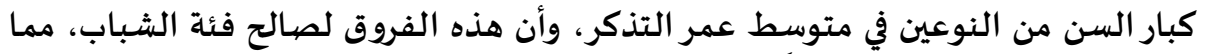

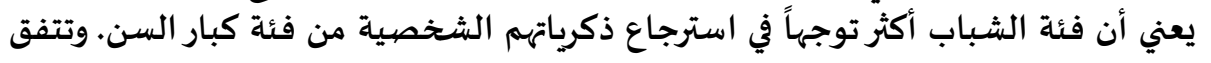




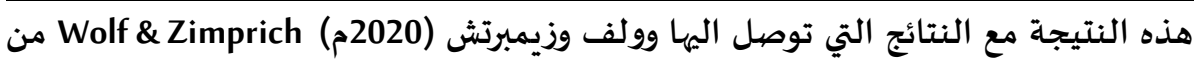

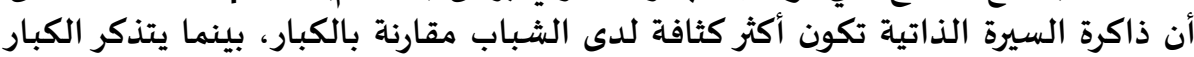

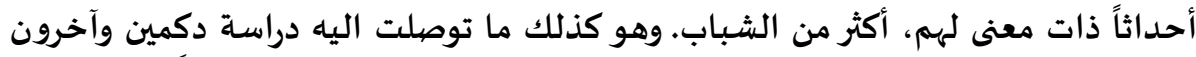
من أن أداء كبار السن كان أقل من الأصغر سناً في استرجاع من أخرون Dikmen et al., (2014)

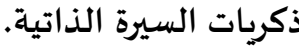

السؤال الرابع: ولإجابة على السؤال الرابع والذي ينص التصائ على: هل يعتبر المستوى

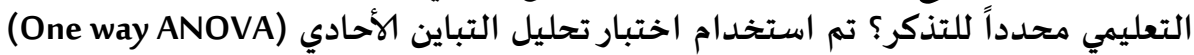

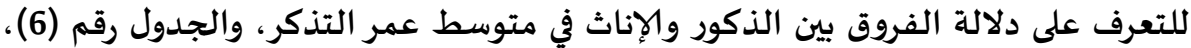
يوضج نتيجة ذلك.

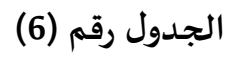

تحليل التباين الأحادي لأثر متغير المستوى الدراسي على عمر التذكر لدى المشـاركين في

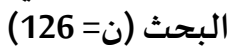

\begin{tabular}{|c|c|c|c|c|c|}
\hline الإحصائية & قيمة ف & متوسط المربعات & دالحربة & مجمبعوع & مصيدر التباين \\
\hline \multirow{2}{*}{$*^{*} 0.05$} & \multirow{2}{*}{2.11} & 5.77 & 8 & 46.16 & المجموعات \\
\hline & & 2.98 & 117 & 348.47 & 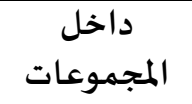 \\
\hline & & & 125 & 394.64 & الكلي \\
\hline
\end{tabular}

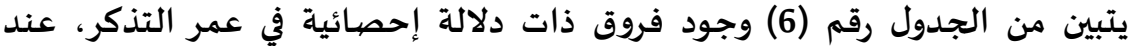

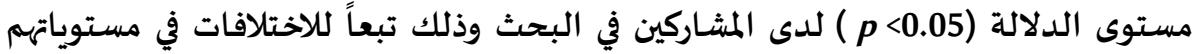

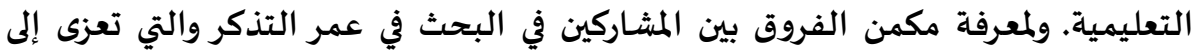

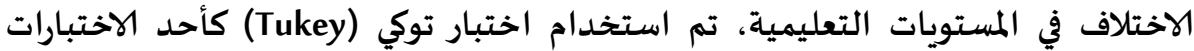

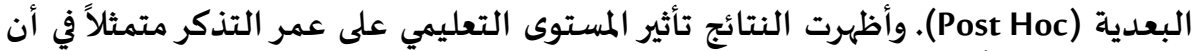

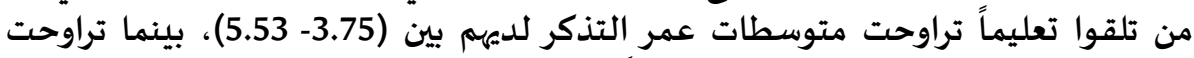

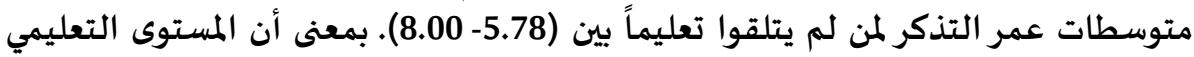

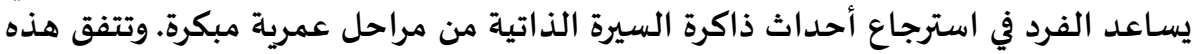

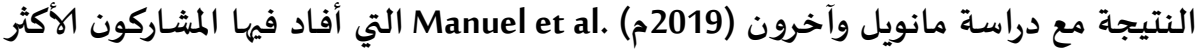

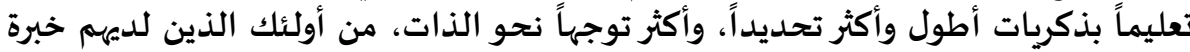




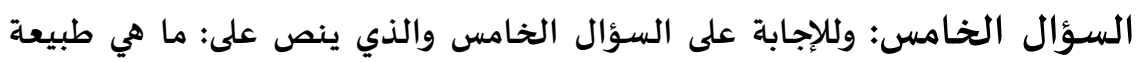

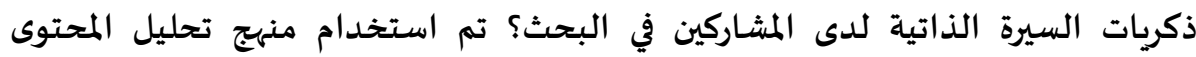

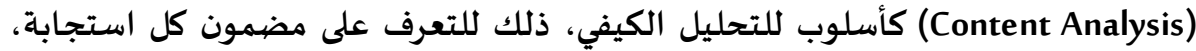

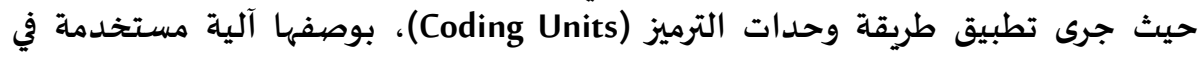

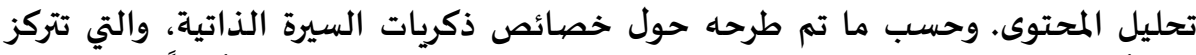

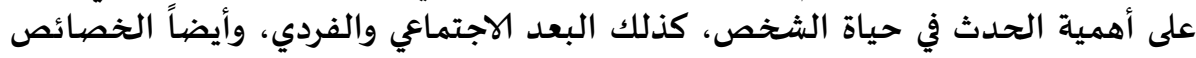

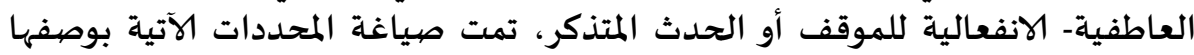

$$
\begin{aligned}
& \text { وحدات للترميز: } \\
& \text { - } \\
& \text { - - الطبيعة الانفعالية - } \\
& \text { - } \\
& \text { - - }
\end{aligned}
$$

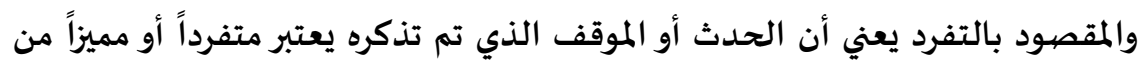

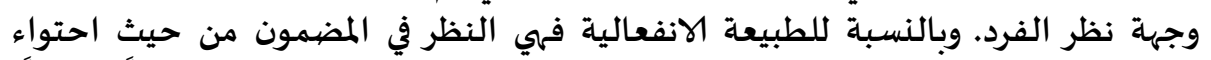

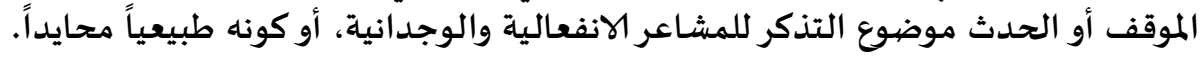

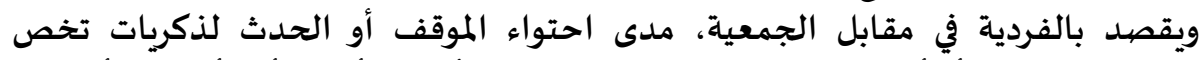

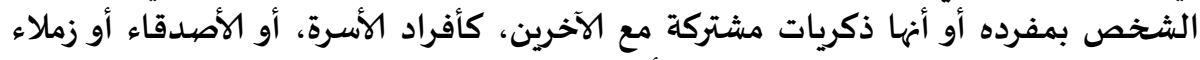

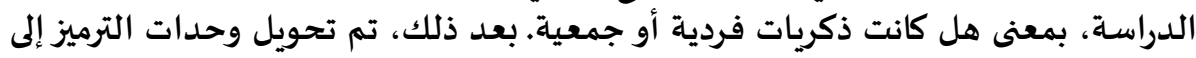

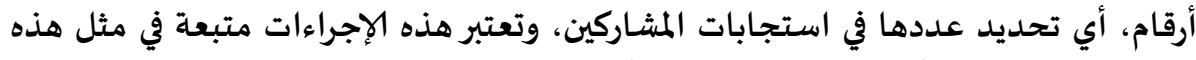

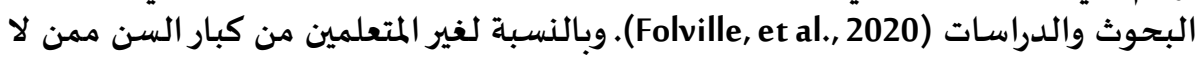

\begin{tabular}{|c|c|c|}
\hline النسبة المئوية & التكرار & وحدات الترميز \\
\hline$\% 23.81$ & 30 & التفرد والأهمية \\
\hline$\% 27.78$ & 35 & الطبيعة الانفعالية \\
\hline$\% 2.52$ & 2 & الفردية \\
\hline$\% 46.83$ & 59 & الجمعية \\
\hline
\end{tabular}

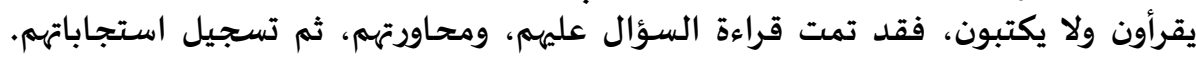

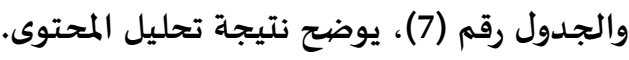

$$
\text { الجدول رقم (7) }
$$

تحليل المحتوى لذكريات السيرة الذاتية لدى المشاركين في البحث (ن= 126)

يتضح من الجدول رقم (7) أن الجانب الاجتماعي يغلب على محتوى ذإئه ذكريات

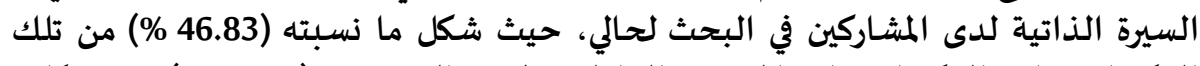

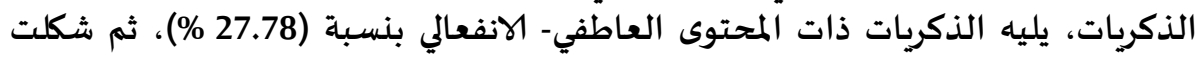


الأحداث والمواقف ذات التفرد والأهمية بالنسبة للفرد ما نسبته (23.81 \%) من ذكرئة الفريات

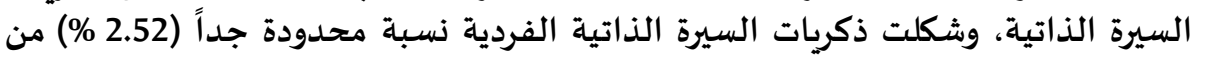

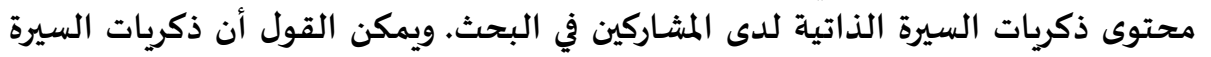

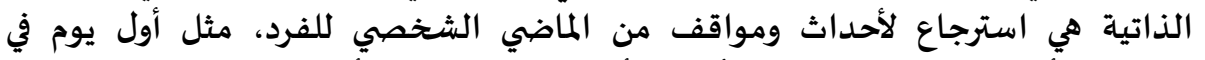

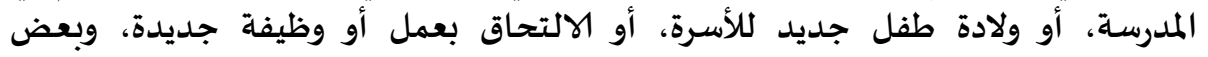

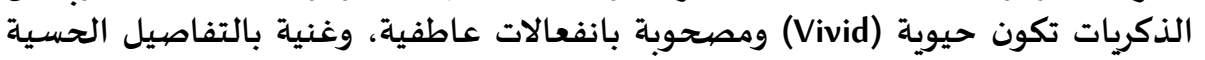

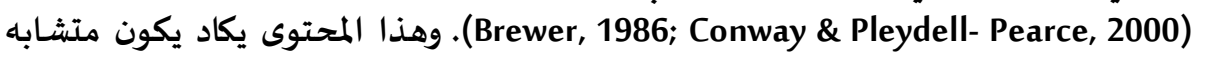

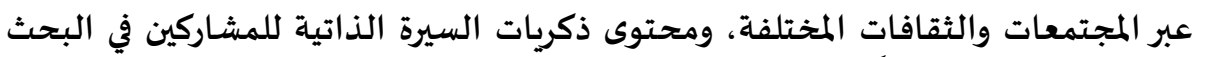

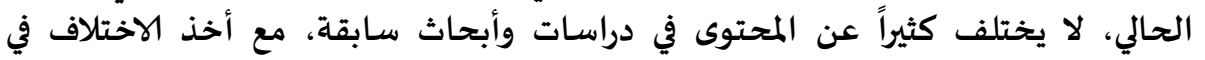

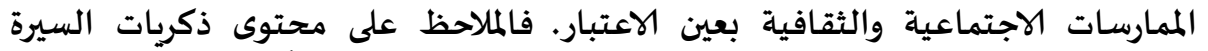

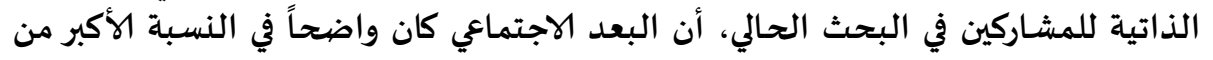

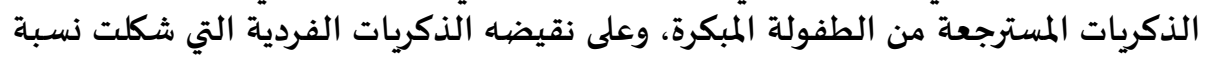

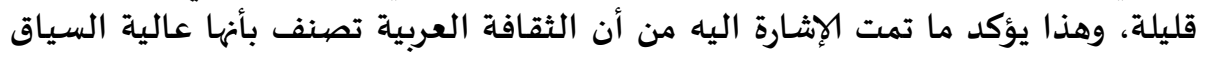

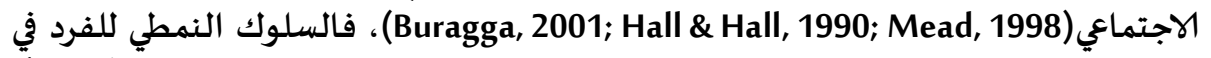

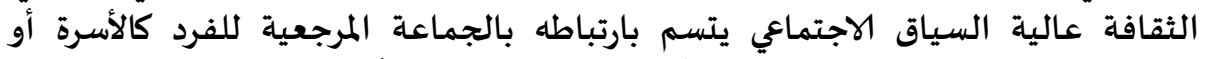

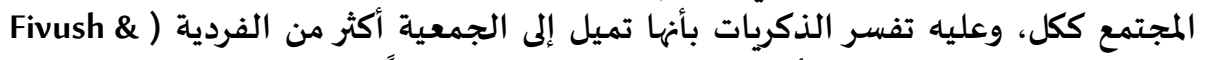

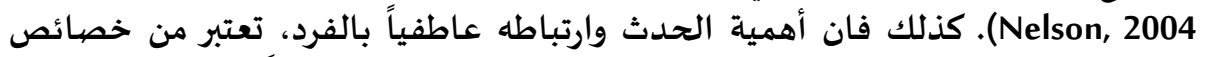

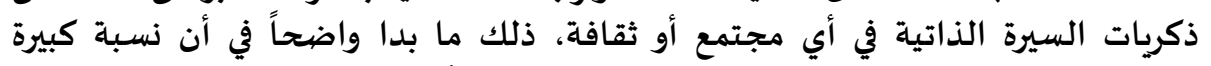

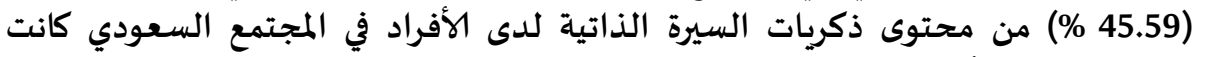
عاطفية وتشكل أهمية بالنسبة للفرد.

$$
\text { الخلاصة والتوصيات: }
$$

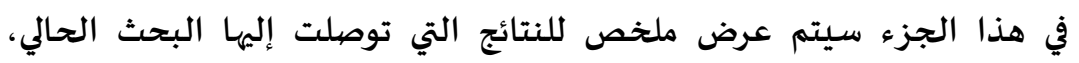

$$
\text { والتوصيات التي يمكن الخروج بها: }
$$

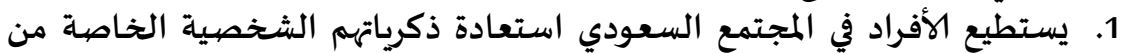

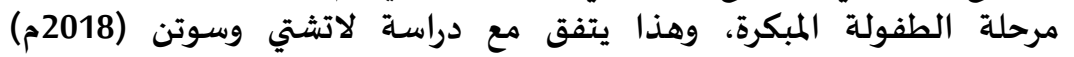
Luchetti \& Sutin

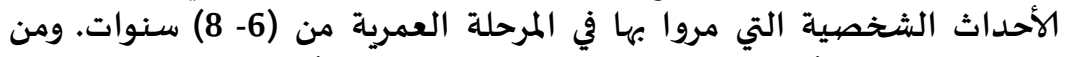

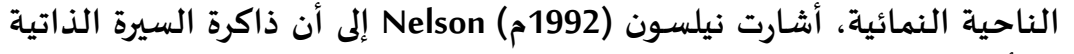

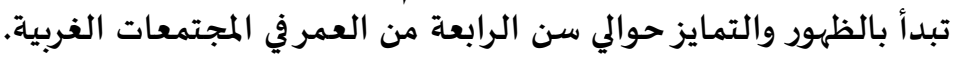

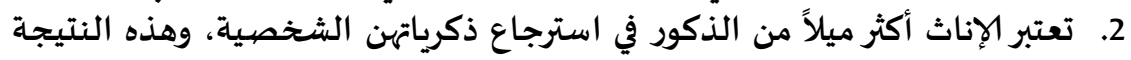

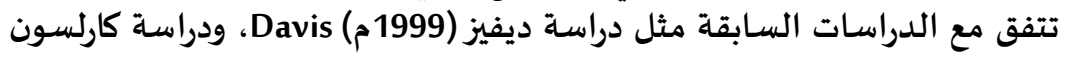

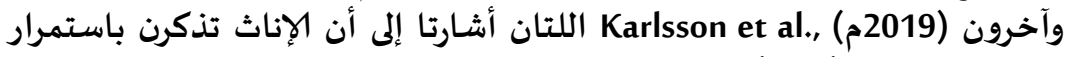

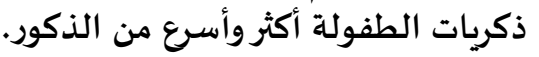

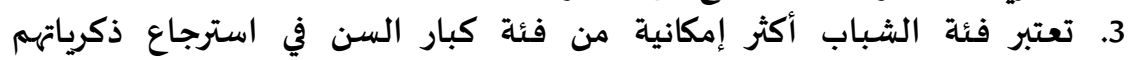

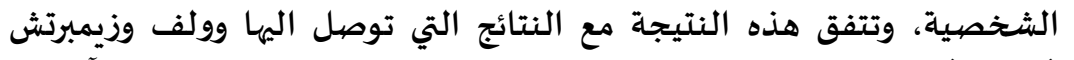
وكذلك ما توصلت اليه دراسة دكمين وآخرون 
من أن أداء كبار السن كان أقل من الأصغر سناً في Dikmen et al., (الذي استرجاع ذكريات السيرة الذاتية.

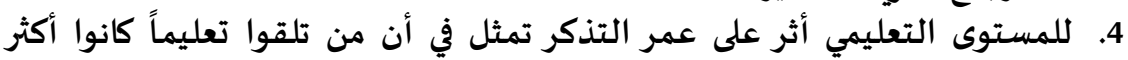

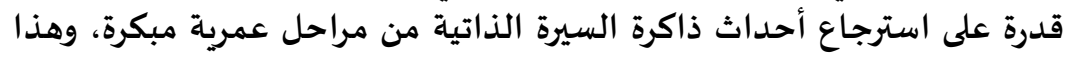

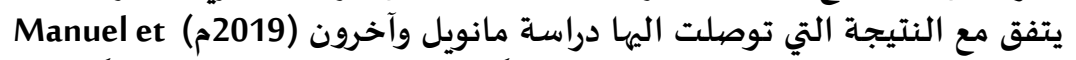
توجها al.,

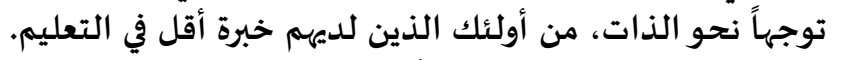

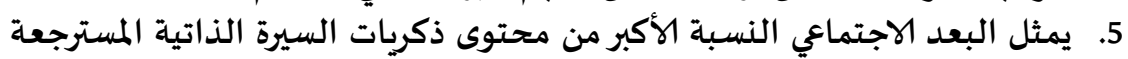

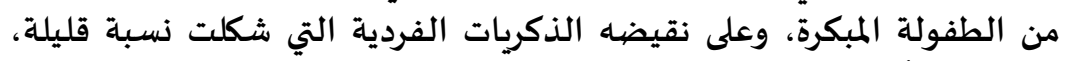

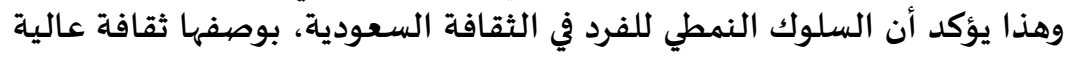

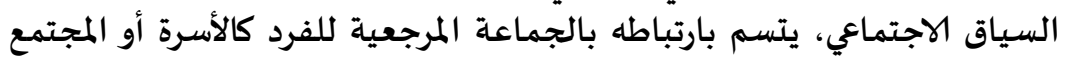

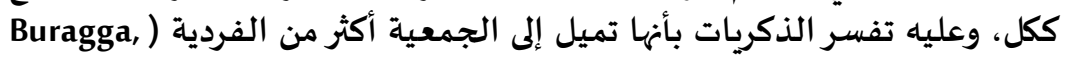
(2001; Hall \& Hall, 1990; Mead, 1998; Fivush \& Nelson, 2004

6. نسبة كبيرة من محتوى ذكريات السيرة الذاتية لدى الأفراد في المجتمع السعودي

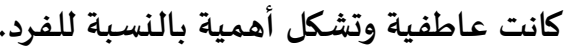

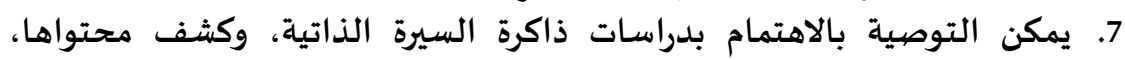

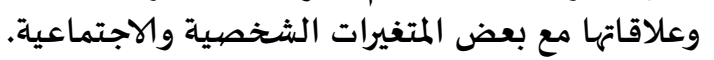

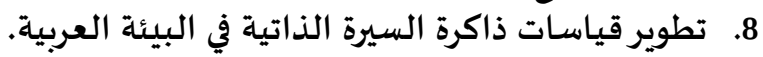

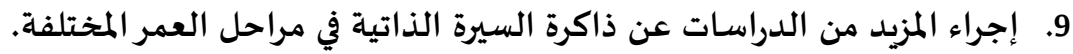

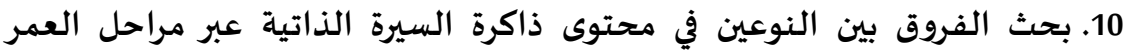

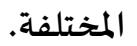

11. الكشف عن أثر الخبرة التعليمية على محتوى وتنظيم ذكريات السيرة الذاتية.

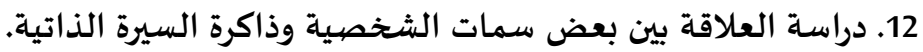

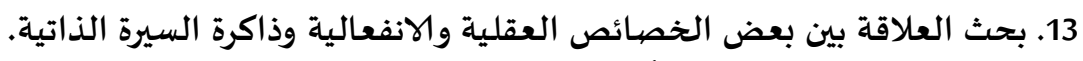
14. دراسة العلاقة بين بعض العلاقين بأمراض النفسية والمشكلات السلوكية وذاكرة السيرة الذاتية. 


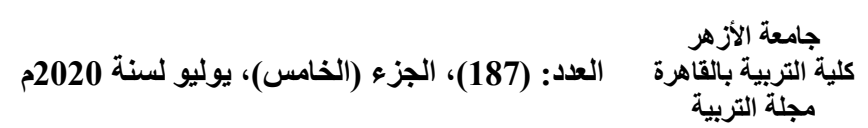

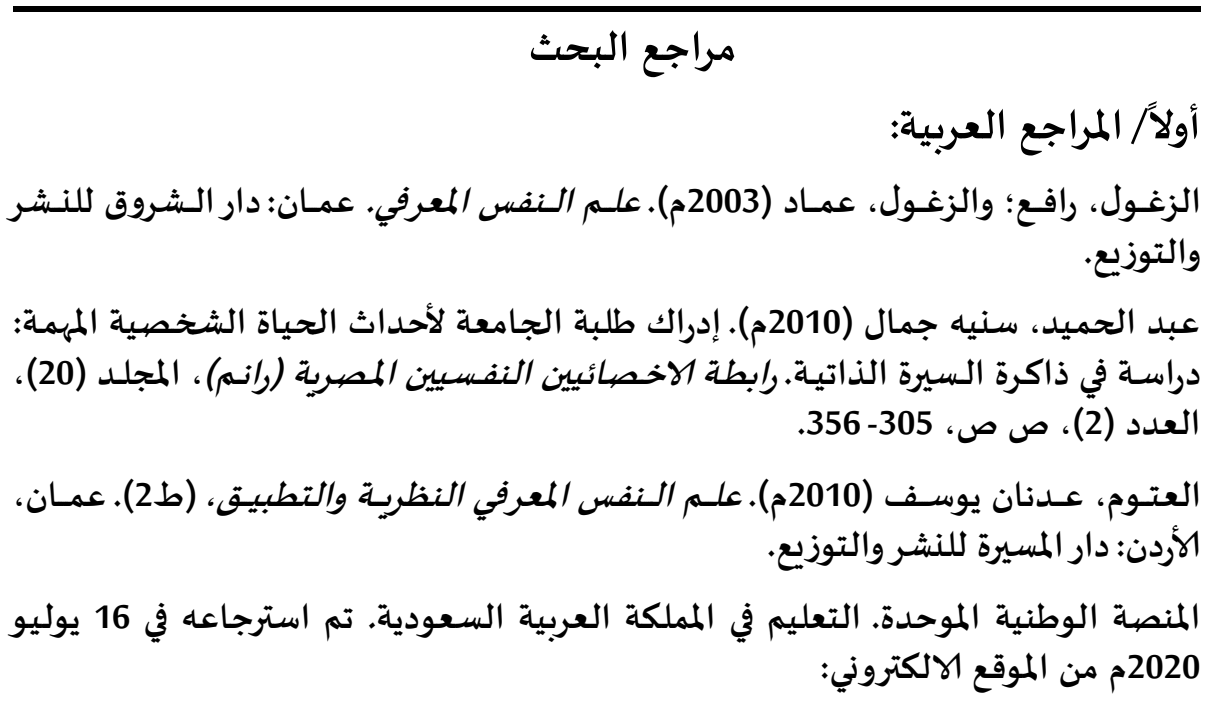

\section{https://www.my.gov.sa/wps/portal/snp/aboutksa/EducationInKSA}

$$
\text { ثانياً/ المراجع الأجنبية: }
$$

Al-Namlah, A. S., Meins, E., \& Fernyhough, C. (2012). Self-regulatory private speech relates to children's recall and organization of autobiographical memories. Early Childhood Research Quarterly, 27(3), 441-446.

Anderson, S. J. \& Conway, M. A. (1997). Representations of autobiographical memories. In M. A. Conway (Ed.), Cognitive Models of Memory. Hove East Sussex: Psychology Press, Publishers.

Anderson, S. J. \& Conway, M. A. (1997). Representations of autobiographical memories. In M. A. Conway (Ed.), Cognitive Models of Memory. Hove East Sussex: Psychology Press, Publishers.

Baddeley, A. D. (1990). Working memory. Oxford: Oxford University Press.

Baddeley, A. D. (1993). Working Memory and Conscious Awareness. In A. F. Collins, S. E. Gathercole, M. A. Conway \& P. E. Morris (Eds, Theories of Memory. Hove East Sussex: Lawrence Erlbaum Assoc.

Baddeley, A. D. (2000). Short-Term and Working Memory. In E. Tulving \& F. I. M. Craik (Eds.), The Oxford Handbook of Memory. New York: Oxford University Press, Inc.

Barsalou, L. W. (1988). The content and organization of autobiographical memories. In U. Neisser \& E. Winograd (Eds.), Remembering reconsidered: Ecological and traditional approaches to the study of memory. Cambridge, England: Cambridge University Press.

Bartlett, F. C. (1932). Remembering. Cambridge: Cambridge University Press. 
Bartlett, F. C. (1937). Psychological methods and anthropological problems. Africa 10, 401-420.

Berntsen, D., \& Rubin, D. C. (2004). Cultural life scripts structure recall from autobiographical memory. Memory \& Cognition, 32(3), 427442.

Brewer, W. F. (1986). What is autobiographical memory? In D. C. Rubin (Ed.), Autobiographical memory. Cambridge, England: Cambridge University Press.

Brown, N. R., Shevell, S. K. \& Rips, L. J. (1986). Public memories and their personal context. In D. C. Rubin (Ed.), Autobiographical memory. Cambridge, England: Cambridge University Press.

Buragga, K. A. (2001). An investigation of the relationship between national culture and the adoption of information technology. Unpublished $\mathrm{PhD}$ dissertation, George Mason University, USA.

Chronological Age: Definition \& Explanation. Retrieved on July 15, 2020, from https://study.com/academy/lesson/chronological-age-definitionlesson-quiz.html (2020).

Chronological Aging and Biological Aging. Retrieved on July 15, 2020, from https://www.healthline.com/health/chronological-ageing (2020).

Conway, M. A. \& Rubin, D. C. (1993). The Structure of Autobiographical Memory. In A. F. Collins, S. E. Gathercole, M. A. Conway \& P. E. Morris (Eds.), Theories of Memory. Hove East Sussex: Lawrence Erlbaum Assoc.

Conway, M. A. \& Rubin, D. C. (1993). The Structure of Autobiographical Memory. In A. F. Collins, S. E. Gathercole, M. A. Conway \& P. E. Morris (Eds.), Theories of Memory. Hove East Sussex: Lawrence Erlbaum Assoc.

Conway, M. A. \& Rubin, D. C. (1993). The Structure of Autobiographical Memory. In A. F. Collins, S. E. Gathercole, M. A. Conway \& P. E. Morris (Eds.), Theories of Memory. Hove East Sussex: Lawrence Erlbaum Assoc.

Conway, M. A. (1990). Associations between autobiographical memories and concepts. Journal of Experimental Psychology: Learning, Memory and Cognition, 16, 799-812.

Conway, M. A., \& Fthenaki, A. (2000). Disruption and loss of autobiographical memory. In L. S. Cermak (Ed.), Handbook of neuropsychology. Handbook of neuropsychology: Memory and its disorders (p. 281-312).

Conway, M. A., \& Pleydell-Pearce, C. W. (2000). The construction of autobiographical memories in the self-memory system. Psychological Review, 107(2), 261-288.

Conway, M. A., Singer, J. A., \& Tagini, A. (2004). The self and autobiographical memory: Correspondence and coherence. Social Cognition, 22(5), 491-529.

Davis, P. J. (1999). Gender differences in autobiographical memory for childhood emotional experiences. Journal of Personality and Social Psychology, 76(3), 498-510. 
Dikmen, S. S., Bauer, P. J., Weintraub, S., Mungas, D., Slotkin, J., Beaumont, J. L., Gershon, R., Temkin, N. R., \& Heaton, R. K. (2014).

Measuring episodic memory across the lifespan: NIH Toolbox Picture Sequence Memory Test. Journal of the International Neuropsychological Society: JINS, 20 (6), 611-619.

Fivush, R (1997). Event memory in early childhood. In, N. Cowan (Ed) The Development of Memory In Childhood. Hove East Sussex: Psychology Press, Publishers.

Fivush, R. \& Hamond, N. R. (1989). Time and again: Effects of repetition and retention interval on 2-year-olds' event recall. Journal of Experimental Child Psychology, 47, 259-273.

Fivush, R. \& Hamond, N. R. (1990). Autobiographical memory across the preschool years: Towards reconceptualizing childhood amnesia. In R. Fivush \& J. Hudson (Eds.), Knowing and remembering in young children. New York: Cambridge University Press.

Fivush, R. \& Nelson, K. (2004). Culture and Language in the Emergence of Autobiographical Memory. Psychological Science, Vol. (15), (9), 573577.

Fivush, R. (1991). The social construction of personal narratives. MerrillPalmer Quarterly, 37,59-81.

Fivush, R., Gray, J. T. \& Fromhoff, F. A. (1987). Two year olds talk about the past. Cognitive Development, 2, 393-410.

Fivush, R., Haden, C., \& Adam, S. (1995). Structure and coherence of preschoolers' personal narratives over time: Implications for childhood amnesia. Journal of Experimental Child Psychology, 60, 32-56.

Flavell, J. H., Friedrichs, A. G. \& Hoyt, J. D. (1970). Developmental changes in memorization processes. Cognitive Psychology, 1, 324-340.

Folville, A., Bahri, M. A., Delhaye, E., Salmon E., D’Argembeau, A. \& Bastin, C. (2020). Age-related differences in the neural correlates of vivid remembering. Neuroimage, Vol. (206), 1-9.

Freud, S. (1953). Three essays on the theory of sexuality. In J. Strachey (Ed.), The standardized edition of the complete psychological works of Sigmund Freud, Vol. 7. London: Hogarth Press. (Original work published 1905).

Gallo, D. A., Korthauer, L. E., McDonough, I. M., Teshale, S. and Johnson, E. L (2013). Age-Related Positivity Effects and Autobiographical Memory Detail: Evidence from a Past/Future Source Memory Task. Memory. Vol. 19(6): 641-652.

Gathercole, S. E. (1998). The development of memory. Journal of Child Psychology and Psychiatry, 39 (1), 3-27.

Glenberg, A. \& Adams, F. (1978). Type 1 rehearsal and recognition. Journal of verbal learning and verbal behavior, 17, 455-463. 
Grossberg, S. (1971). "Pavlovian pattern learning by nonlinear neural networks". Proceedings of the National Academy of Sciences 68 (4): 828-31

Hall, E. T. \& Hall M. R. (1990). Understanding Cultural Differences: Germans, French and American. Yarmouth, Maine: Intercultural press, Inc.

Han, J. J., Leichtman, M.D. \& Wang, Q. (1998). Autobiographical memory in Korean, Chinese and American children. Developmental Psychology, 34 (4), 701-713.

Han, J. J., Leichtman, M.D. \& Wang, Q. (1998). Autobiographical memory in Korean, Chinese and American children. Developmental Psychology, 34 (4), 701-713.

Howe, M. L. \& Courage, M. L. (1993). On resolving the enigma of infantile amnesia. Psychological Bulletin, 113, 305-326.

Hudson, J A. \& Nelson, K. (1986). Repeated encounters of a similar kind: Effects of familiarity on children's autobiographical memory: Cognitive Development, 1, 253-271.

Hudson, J A. \& Nelson, K. (1986). Repeated encounters of a similar kind: Effects of familiarity on children's autobiographical memory: Cognitive Development, 1, 253-271.

Hudson, J. A. (1990). The emergence of autobiographical memory in mother-child conversation. In R. Fivush \& J. Hudson (Eds.), Knowing and remembering in young children. New York: Cambridge University Press.

Karlsson, Kristina P., Sverker, Sikström, Fredrik U., Jönsson, Marie Gustafsson Sendén \& Johan Willander (2019). Gender differences in autobiographical memory: females latently express communality more than do males, Journal of Cognitive Psychology, 31:7, 651-664.

Laboratory of comparative human cognition (1979). Cross-cultural psychology's challenges to our ideas of children and development. American Psychologist 34, 827-833.

Laboratory of comparative human cognition (1983). Culture and cognitive development. In Handbook of child psychology, P. H. Mussen (Ed.), Vol. I of History, theory, and methods, W. Kessen (Ed.). New York: Wiley.

Lewis, M. \& Brooks-Gunn, J. (1979). Social cognition and the acquisition of the self. New York: Plenum.

Linton, M. (1986). Ways of searching and the contents of memory. In D. C. Rubin (Ed.), Autobiographical memory. Cambridge, England: Cambridge University Press.

Luchetti, M., \& Sutin, A. R. (2018). Age differences in autobiographical memory across the adult lifespan: Older adults report stronger phenomenology. Memory, 26(1), 117-130.

Mair, Ali (2017). Effects of age on autobiographical memory. (Unpublished Doctoral thesis, City, University of London). 
Manuel L. de la Mata, Andrés Santamaría, Eva M ${ }^{\text {a }}$ Trigo, Mercedes Cubero, Samuel Arias-Sánchez, Radka Antalíková, Tia G.B. Hansen \& Marcia L. Ruiz (2019). The relationship between sociocultural factors and autobiographical memories from childhood: the role of formal schooling, Memory, 27:1, 103-114.

Martina Luchetti \& Angelina R. Sutin (2018). Age differences in autobiographical memory across the adult lifespan: older adults report stronger phenomenology, Memory, 26:1, 117-130.

Mead, G. H. (1984). Mind, self and society from the standpoint of a social behaviourist. Chicago: University of Chicago Press.

Mead, R. (1998). International Management, cross-cultural dimensions. Oxford: Blackwell Publishers Ltd.

Mongillo, G.; Barak, O.; Tsodyks, M. (2008). "Synaptic theory of working memory". Science 319 (5869): 1543-6

Mullen, M. K. \& Yi, S. (1995). The cultural context of talk about the past: Implications for the development of autobiographical memory. Cognitive Development, 10, 407-419.

Nadel, L. \& Zola-Morgan, S. (1984). Infantile amnesia: A neurobiological perspective. In M. Moscovitch (Ed.), Infant memory. New York: Plenum Press.

Nelson, K. \& Fivush, R. (2000). Socialisation of memory. In E. Tulving \& F. I. M. Craik (Eds.), The Oxford Handbook of Memory. New York: Oxford University Press, Inc.

Nelson, K. \& Gruendel, J. (1981). Generalized event representations: Basic building blocks of cognitive development. In M. Lamb \& A. Brown (Ed.), Advances in developmental psychology, Vol. 1. Hillsdale, NJ: Lawrence Erlbaum Associates Inc.

Nelson, K. \& Gruendel, J. (1981). Generalized event representations: Basic building blocks of cognitive development. In M. Lamb \& A. Brown (Ed.), Advances in developmental psychology, Vol. 1. Hillsdale, NJ: Lawrence Erlbaum Associates Inc.

Nelson, K. \& Ross, G. (1980). The generalities and specifics of long term memory in infants and young children. In M. Perlmutter (Ed.), Children's memory: New directions for child development, Vol. 10. San Francisco: Jossey-Bass.

Nelson, K. \& Ross, G. (1980). The generalities and specifics of long term memory in infants and young children. In M. Perlmutter (Ed.), Children's memory: New directions for child development, Vol. 10. San Francisco: Jossey-Bass.

Nelson, K. (1989). Monologues in the crib. In K. Nelson (Ed.), Narratives from the crib. Cambridge, MA: Harvard University Press.

Nelson, K. (1990). Remembering, forgetting and childhood amnesia. In R. Fivush \& J. Hudson (Eds.), Knowing and remembering in young children. New York: Cambridge University Press. 
Nelson, K. (1992). Emergence of autobiographical memory at age 4. Human Development, 35, 172-177.

Nelson, K. (1993). The psychological and social origins of autobiographical memory. Psychological Science, 4, (1), 7-14.

Nelson, K. (1993a). The psychological and social origins of autobiographical memory. Psychological Science, 4, (1), 7-14.

Nelson, K. (1993b). Events, Narratives, Memory: What Develops? Minnesota Symposia on Child Psychology, 26, 1-24.

Nelson, K. (1993c). Explaining the emergence of autobiographical memory in early childhood. In A. F. Collins, S. E. Gathercole, M. A. Conway \& P. E. Morris (Eds.), Theories of Memory. Hove East Sussex: Lawrence Erlbaum Assoc.

Ornstein, P. A., Naus, M. J., \& Liberty, C. (1975). Rehearsal and organization processes in children's memory. Child Development, 46, 818-830.

Perner, J. \& Ruffman, T. (1995). Episodic memory: An autonoetic consciousness: Developmental evidence and a theory of childhood amnesia. Experimental Child Psychology, 59, 516-548.

Pillemer, D. B. \& White, S. H. (1989). Childhood events recalled by children and adults. Advances in Child Development and Behavior, 21, 297340 .

Pillemer, D. B. (1998). Momentous events, vivid memories. Cambridge, MA: Harvard University Press.

Rugg MD, Wilding EL. Retrieval processing and episodic memory. Trends Cogn Sci. 2000; 4(3):108-115.

Schank, R. C. \& Abelson, R. P. (1977). Scripts, plans, goals and understanding. Hillsdale, NJ: Lawrence Erlbaum Assoc.

Schlagman, S., Kvavilashvili, L., \& Schulz, J. (2007). Effects of age on involuntary autobiographical memories. In J. H. Mace (Ed.), New perspectives in cognitive psychology. Involuntary memory (p. 87112). Blackwell Publishing.

Schooler, J. W. \& Hermann, D. J. (1992). There is more to episodic memory than just episodes. In M. A. Conway, D. C. Rubin, H. Spinnler \& W. A. Wagenaar (Eds.), Theoretical perspectives on autobiographical memory. Dordrecht, The Netherlands: Kluwer Academic.

Sheldon, S., Williams, K., Harrington A. S. \& Otto, R. (2020). Emotional cue effects on accessing and elaborating upon autobiographical memories. Cognition, Vol. 198

St. Jacques, P. L. and Levine, B. (2007). Ageing and autobiographical memory for emotional and neutral events. Memory. Vol. 15 (2), 129144.

Thompson, C. P., Skowronski, J. J., Larsen, S. F. \& Betz, A. L., (1996). Autobiographical memory: Remembering what and remembering when. Mahwah: Lawrence Erlbaum Assoc. 
Tulving, E. (1972). Episodic and semantic memory. In E. Tulving \& W. Donaldson (Eds.), Organization of memory. New York: Academic Press.

Tulving, E. (1983). Elements of Episodic Memory. Oxford: Clarendon Press.

UNESCO, Retrieved on July 16, 2020, from http://www.ibe.unesco.org/en/glossary-curriculumterminology/l/levels-education

Vygotsky, L. S. (1978). Mind in society: The development of higher psychological processes. (M. Cole, V. John-Steiner, S. Scribner and E. Souberman, eds.). Cambridge, MA: The MIT Press.

Vygotsky, L. S. (1999). Thought and Language. Eleventh printing, newly revised and edited by: A. Kozulin, Cambridge, MA: The MIT Press.

Walls, R. T., Sperling, R. A. \& Weber, K. (2001). Autobiographical Memory of School. The Journal of Educational Research, Vol. 95 (2):116-127.

Wang, Q. (2016). Remembering the self in cultural contexts: A cultural dynamic theory of autobiographical memory. Memory Studies, Vol. (9), (3), 295-304.

Williams, J. M. G., Barnhofer, T., Crane, C., Herman, D., Raes, F., Watkins, E., \& Dalgleish, T. (2007). Autobiographical memory specificity and emotional disorder. Psychological Bulletin, 133(1), 122-148.

Wolf, T. \& Zimprich D. (2016). How can individual differences in autobiographical memory distributions of older adults be explained? Memory, Vol. 24, NO. 9, 1287-1299.

Wolf, T. \& Zimprich D. (2020). What characterizes the reminiscence bump in autobiographical memory? New answers to an old question. Memory \& Cognition, Vol. 48, 607-622.

Wood, J. (2018). What's Your Earliest Memory? Psych Central. Retrieved on July 15, 2020, from: https://psychcentral.com/news/2014/01/26/whats-your-earliestmemory/64982.html

World Health Organization. Early child development. Retrieved on July 28, 2020, from: https://www.who.int/topics/early-child-development/en/ 